\title{
Experimental study on percolation mechanism and displacement characteristics of cold recovery in offshore heavy oil field
}

\author{
Ying-xian Liu ${ }^{1} \cdot$ Jie Tan $^{1}{ }^{1} \cdot$ Hui Cai ${ }^{1}$. Gong-chang Wang ${ }^{1} \cdot$ Song-ru Mou ${ }^{1}$
}

Received: 17 June 2021 / Accepted: 26 August 2021 / Published online: 5 September 2021

(c) The Author(s) 2021

\begin{abstract}
The heavy oil reservoir is a special kind of oil and gas reservoir that differs from the conventional reservoir in many ways. Due to the high viscosity of crude oil, it is not easy to recover. When the viscosity of underground crude oil exceeds $150 \mathrm{cp}$, the land heavy oil field is generally developed by thermal recovery. S.Z. oilfield is a heavy oil reservoir in the Bohai Sea, with surface crude oil viscosity of 3000-25,000 cp and underground crude oil viscosity of 400-1000 cp. Limited by offshore equipment, the development strategy of land oilfields can't be directly applied. High production capacity is obtained through the cold production development of horizontal branch experimental wells, and the water drive production capacity can reach 40-70 $\mathrm{m}^{3} /$ day. At present, there is a lack of research on cold recovery development under the viscosity of crude oil. The existing primary research and common knowledge are challenging to support efficient development technology for effectively producing heavy oil reservoirs. In this paper, through physical simulation experiments, the phase behavior and rheological properties of crude oil in the target block are studied, and the rheological properties of crude oil are clarified. Then, the depletion production and water flooding experiments are carried out, and the displacement characteristics and laws of water flooding cold production are analyzed. Finally, the indoor experiments of water flooding sweep efficiency and oil displacement efficiency in the target block are carried out. Clear its micro and macro spread. It provides technical support for the effective production of offshore heavy oil fields.
\end{abstract}

Keywords Offshore oilfield $\cdot$ Heavy oil $\cdot$ Cold recovery $\cdot$ Seepage mechanism $\cdot$ Displacement characteristics

\section{Preface}

\section{Factors affecting cold heavy oil recovery}

\section{Heavy oil viscosity}

The researchers' analysis shows that due to the viscosity anomaly of heavy oil, the oil recovery rate of the heavy oil reservoir is much lower than that of the reservoir without abnormal viscosity under seepage conditions because of the abnormal viscosity of heavy oil, which destroys Newton law and Darcy seepage law. In 1960, former Soviet scholar B. H. Sultanov proposed that crude oil belongs to non-Newtonian fluid, and many scholars at home and abroad have carried

Jie Tan

4687610@qq.com

1 Bohai Petroleum Research Institute, Tianjin Branch of CNOOC Ltd., Tianjin, China out experiments and numerical studies (Mai and Kantzas 2009; Liu et al. 2013).

Through experiments, it is concluded that the underground seepage of heavy oil meets the seepage law of Bingham fluid in the non-Newtonian fluid. There is an initial pressure gradient in the seepage process, and its value is about $104 \mathrm{kPa} / \mathrm{M}$. Although the concept of starting pressure is proposed in this paper, there is no quantitative study and description due to the difference of reservoir types in the study of the starting pressure gradient. In 1997, Huang Yanzhang and Bai Baojun deduced the expression of initial pressure gradient, respectively, based on experiments (Sheng et al. 1997; Adams 1982; Zheng and Yang 2013).

In the 1960s, non-Newtonian fluids were used in oil fields, such as polymer solution, micelle solution, foam liquid, and emulsion as oil displacement agents. These are non-Newtonian fluids. With the development of the global economy, the demand for oil in the world is increasing rapidly. The heavy oil resources attract the attention of the world with their abundant reserves. Therefore, people began to study 
the characteristics and seepage law of heavy oil. Heavy oil, as a kind of non-Newtonian fluid, has its unique flow and rheological characteristics. Rheology refers to the deformation or flow of material or a material system under the force or force system, flow deformation. The equation describing the rheological behavior is called the constitutive equation or rheological equation of state. Non-Newtonian fluid can be divided into pure viscous and viscoelastic; pure viscous nonNewtonian fluid refers to any fluid that cannot be recovered after the shear force is removed, including pure viscous fluid independent of time. This fluid has pseudo-plasticity, expansibility, Bingham, quasi yield plasticity, and yield expansion. The time-related pure viscous fluid has thixotropic (thixotropic) and shock condensation (thixotropy). Viscoelastic non-Newtonian fluid is a fluid that can be partially recovered after the shear force is removed (Singhal 2009; Zheng 2015; Guo 2014; Zhang 2007).

\section{Natural of porous media}

Unlike conventional thin oil, heavy oil has a high viscosity, significant molecular weight, and strong polarity, and the interaction force between crude oil and rock interface and between crude oil is large, which leads to the seepage of heavy oil deviates from Darcy law. This kind of seepage has the starting pressure gradient non-Darcy seepage. When the driving pressure gradient exceeds the initial pressure gradient, the heavy oil could flow (Sun 2017; Li 2016; Yu 2017).

Different scholars have different viewpoints on the causes of the starting pressure gradient. There are three primary schools: fluid theory, media theory, and absorbing water theory. According to the fluid theory, the rheological behavior of non-Newtonian fluid is the leading cause of starting pressure gradient. The medium theory holds that the nature of porous medium would affect the interaction force between fluid and porous medium. The influence of this force would form a stable gel film on the surface of crude oil and porous medium so that the gelatin membrane partly covers the pores of rocks, and the flow of fluid in the rock must be destroyed - the reason for the starting pressure gradient. According to the theory of water absorption, there is a water absorption layer on the surface of medium particles, which would produce resistance to fluid flow. The flow of fluid in the medium needs to overcome this resistance, which is why the generation of starting pressure gradient (Zheng 2013; Cheng 2020).

Alvaro praday has conducted single-phase experimental seepage research on artificially cemented cores and natural cores with different permeability. It is obtained that under low-speed seepage, the seepage curve presents a nonlinear relationship with the increase in seepage speed, the seepage curve transitions to a linear section. The same liquid shows different seepage characteristics in different media, which fully shows that the pore structure characteristics of porous media have an important influence on the seepage velocity of low-speed non-Darcy flow (Wang 2015; Yan et al. 2015).

\section{History of the previous studies and field applications}

At present, the development of similar heavy oil reservoirs mainly adopts thermal production development, and there are few examples of cold production development results. Some heavy oil fields in Canada have achieved good development results through injection and production.

The viscosity of underground crude oil in the Niuxintuo oilfield is above $400 \mathrm{cp}\left(65^{\circ} \mathrm{C}\right)$. The comparison of data before and after cold production shows that the oil production volume of the well increases $148.1 \mathrm{~m}^{3} /$ day and the oil production by $1.1 \mathrm{~m}^{3} /$ day (Zhao 2019; Zhang 2017).

The permeability of the Chenjiazhuang oilfield is $2500 \mathrm{mD}$, the viscosity of surface degassing crude oil $\left(50{ }^{\circ} \mathrm{C}\right)$ is $10,000-30,000 \mathrm{cp}$, and that of crude oil in formation is generally $400-800 \mathrm{cp}$. According to the physical properties of crude oil, the main production processes adopted are high-pressure filling sand control and electric heating rod pumping heavy oil, with a heating power of $50-70 \mathrm{KW}$. The lifting process adopts 12 beam pumping and $57 \mathrm{~mm}$ long barrel pumps, and the operating parameters are $4.2 \mathrm{~m} \times 0.5 \sim 2 \mathrm{r} / \mathrm{min}$. The daily oil output is $5.4 \mathrm{~m}^{3}(\mathrm{Li}$ 2014; Shi 2013).

The permeability of the Gudao oilfield is $1465 \mathrm{mD}$, and the viscosity of surface crude oil is $3300-5500 \mathrm{cp}$. Water injection is developed. The thin and single reservoirs and the viscosity of crude oil is significant. The development effect is poor. Therefore, it is adjusted to thermal production development, with a daily liquid production level of $2766 \mathrm{~m}^{3} /$ day, unit oil production level of $207 \mathrm{~m}^{3} /$ day, average single well daily production capacity of $86 \mathrm{~m}^{3} /$ day, single well daily oil production capacity of $6.3 \mathrm{~m}^{3} /$ day, extended water cut of $94.5 \%$, and cumulative oil production of $147 \times 10^{4} \mathrm{~m}^{3}$, cumulative water yield $1220 \times 10^{4} \mathrm{~m}^{3}$, cumulative water injection $1274 \times 10^{4} \mathrm{~m}^{3}$, recovery degree $18.7 \%$, recovery $25.0 \%$, oil recovery rate $1.0 \%$ (Wu 2007; Qu 2014).

The permeability of Lukeqin heavy oil field in Xinjiang is $98.7-493 \mathrm{mD}$, the viscosity of underground crude oil is $150-500 \mathrm{cp}$, and the water drive viscosity is seriously pointed in, and the output is $4 \mathrm{~m}^{3} /$ day. After nitrogen foam flooding, the average single well increased oil production by $252 \mathrm{~m}^{3}$. In the same year, the cumulative oil increased by $11,573 \mathrm{~m}^{3}$, the oil changing rate was $0.8 \mathrm{~m}^{3} / 100 \mathrm{~m}^{3}$, and the input-output ratio was $1: 1.1$. Therefore, it is estimated that the average cumulative increase of oil in the single well is $406 \mathrm{~m}^{3}$ in the effective period. Through the statistical relationship between daily oil increase and water cut before huff and puff in the initial stage of a single well, it is found that 
the higher the water content is, the more oil increases in the initial stage, the higher the water content and the higher the water cut indicates that the formation pressure is good. Thus, the plugging water mechanism can be entirely played (Wei 2010; Liu 2008).

WTG heavy oil field has a core permeability of $80.8-129.4 \mathrm{mD}$. The surface viscosity is $2000 \mathrm{cp}$, and the viscosity of underground crude oil is $500 \mathrm{cp}$. In the initial injection production and development stage, the daily oil production gradually decreases with the continuous production of production wells. As a result, the increase in cumulative oil production shows a decreasing trend, and the water content shows a gradual upward trend (Tong 2017; Fan et al. 2006).

Scholars have pointed out that the exchange of production wells with injection wells may help oil recovery. This production adjustment mode is called reverse water flooding. Some related experimental results show that when the water content of a heavy oil reservoir reaches a certain extent, the sweep coefficient of injected water can be expanded by adopting the reverse water flooding scheme, and the recovery rate of the reservoir can be further improved. After adopting the reverse water flooding, the sweep coefficient of the injected water in the oilfield has been improved to some extent, and the displacement effect of the water flooding is improved. As a result, the cumulative oil production increased by $0.42 \times 10^{4} \mathrm{~m}^{3}$ at the end of the forecast period, and the recovery degree increased by $0.33 \%$ (Dun et al. 1996).

Mendes et al. conducted a study in the Boskan oilfield in the west of Lake Malakaibo. The reservoir depth is more than $2400 \mathrm{~m}$, the API value is 10.5 , and the viscosity is between 150 and $350 \mathrm{cp}$. It is found that the secondary recovery of the reservoir is improved by using reverse sevenpoint well network water injection (Zhang et al. 1999; Liu 1999).

The Aberfeldy reservoir, big gully North oilfield, golden lake/Maidstone oilfield, tangled flags oilfield, wilder oilfield, Lloydminster oilfield, and soda lake oilfield in Canada were investigated. These oilfields are heavy oil reservoirs, with burial depth of $400-800 \mathrm{~m}$, the permeability of $100-10,000 \mathrm{mD}$, dead oil viscosity of $800-80,000 \mathrm{cp}$, reservoir thickness of 3.5-7 m, and recovery degree failure exploitation of $0.1-1.8 \%$. The horizontal well length of water injection development is $800-2000 \mathrm{~m}$, the well spacing is $50-210 \mathrm{~m}$, and the water injection development production is between 3 and $10 \mathrm{~m}^{3} /$ day. After $0.5 \mathrm{PV}$ water is injected into the horizontal well, the recovery degree is $4-12 \%$, and the expected recovery degree is $5-15 \%$ when $1 \mathrm{pv}$ is injected. Thus, the recovery of water flooding can be increased by $0.4-19.7 \%$, with an average of $8.5 \%(\mathrm{Qu} 2013)$.

The heavy oil reservoir is a special kind of oil and gas reservoir that differs from conventional reservoirs in many ways.
Due to the high viscosity of crude oil, it is not easy to recover. When the viscosity of underground crude oil exceeds $150 \mathrm{cp}$, the land heavy oil field is generally developed by thermal recovery. S.Z. oilfield is a heavy oil reservoir in the Bohai Sea, with surface crude oil viscosity of 3000-25,000 cp and underground crude oil viscosity of 400-1000 cp. Limited by offshore equipment, the development strategy of land oilfields cannot be directly applied. Some scholars have explored the mechanism of heavy oil seepage, but the research is not systematic and in-depth. Some scholars have studied the mechanism of heavy oil seepage, but the research is not systematic and in-depth. In particular, the research on cold recovery development under the crude oil viscosity is relatively scarce, and the existing primary research and common understanding are challenging to support the establishment of efficient development technology for effectively producing heavy oil reservoirs. In this paper, physical simulation experiments are used to carry out depletion production and water displacement experiments, analyze the displacement characteristics and laws of water drive cold production and conduct indoor experiments on water drive sweep coefficient and oil displacement efficiency in the target block. Clarify its micro and macro spread. Provide technical support for effective production of heavy oil.

\section{Reservoir physical properties and fluid properties}

The S.Z. oilfield is a heavy oil reservoir in the Bohai Sea. It is a structural reservoir, delta sedimentary facies, depth $-1450 \mathrm{~m}$, high porosity and permeability, and a normal temperature and pressure system. The viscosity of surface crude oil is as high as 3000-25,000 cp, and that of underground crude oil is $400-1000 \mathrm{cp}$ (Table 1).

\section{Viscosity test, viscosity-temperature test, and rheological properties of heavy oil}

In this chapter, the PVT characteristics, viscosity-temperature characteristics, and rheological characteristics of crude oil are tested using oil samples from heavy oil reservoirs, and the effects of natural gas solubility, temperature, and shear rate on crude oil viscosity under different pressures are clarified.

\section{PVT test of formation crude oil}

\section{Bubble point pressure test method}

Experimental material: Degassed crude oil; petroleum ether; absolute ethanol; toluene.

Experimental instrument: Ultra-high pressure full visual PVT test system, produced in France, model PVT 250/1500 FV, as shown in Fig. 1. The maximum working 


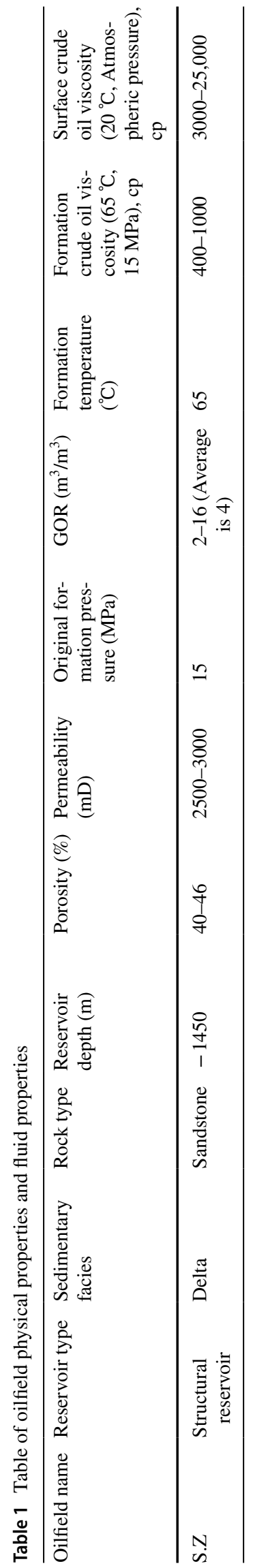

pressure of the instrument is $150 \mathrm{MPa}$, and the maximum working temperature is $200{ }^{\circ} \mathrm{C}$. It can test the temperature, pressure, and volume of different fluids under high temperature and high pressure and analyze the data. The device has a visual window, which can observe fluid state in a PVT cylinder in real-time.

Experimental purpose: Prepare the degassed crude oil and simulated gas into gas-bearing formation crude oil according to the production GOR, analyze the phase characteristics of crude oil under high temperature and high pressure, and clarify the physical properties of crude oil.

Experiment content

1. Preparation of gas-bearing crude oil in formation;

2. Single degassing experiment: test the GOR;

3. Constant mass expansion test: original GOR, dew point pressure, and $\mathrm{P}-\mathrm{V}$ relationship;

\section{Experiment steps}

1. Check the tightness of the PVT kettle body. After ensuring good sealing, inject $40 \mathrm{~mL}$ of dehydrated crude oil into the PVT drum, and inject the required gas volume according to the GOR of 2:1.

2. Set the instrument temperature to $65{ }^{\circ} \mathrm{C}$ and place it for more than $4 \mathrm{H}$ to make the fluid in the PVT cylinder reach the formation temperature.

3. At $65^{\circ} \mathrm{C}$, slowly increase the pressure in the cylinder and reduce the cavity to increase the volume of crude oil by 1-2 MPa each time. During the pressure rise, turn on the mixing function to thoroughly mix the gas and crude oil until the formation pressure reaches $15 \mathrm{MPa}$.

4. Depressurize by withdrawing the pump. During the depressurization process, the instrument can collect the temperature, pressure, and volume in real-time. The depressurization speed is $3 \mathrm{~mL} / \mathrm{h}$. The mixing function is turned off during the depressurization process.

5. Through the computer connected with the PVT instrument, the relationship curve between pressure and crude oil volume is directly drawn, and the relationship curve between volume and pressure is drawn on the coordinate axis. The change of volume and pressure should be two straight lines with different slopes, and the intersection is the bubble point pressure.

6. Repeat step (3) to remix the gas and oil in the PVT cylinder, gradually depressurize at the rate of $6 \mathrm{~mL} / \mathrm{h}$ and process the data according to (5).

7. Repeat step (3), depressurize $1 \mathrm{MPa}$ each time according to the balanced depressurization method, turn on the mixing function at the same time, keep the phase balance of the liquid in the cylinder, record the volume, and process the data according to (5). 
Fig. 1 Ultra-high pressure full visual PVT test system

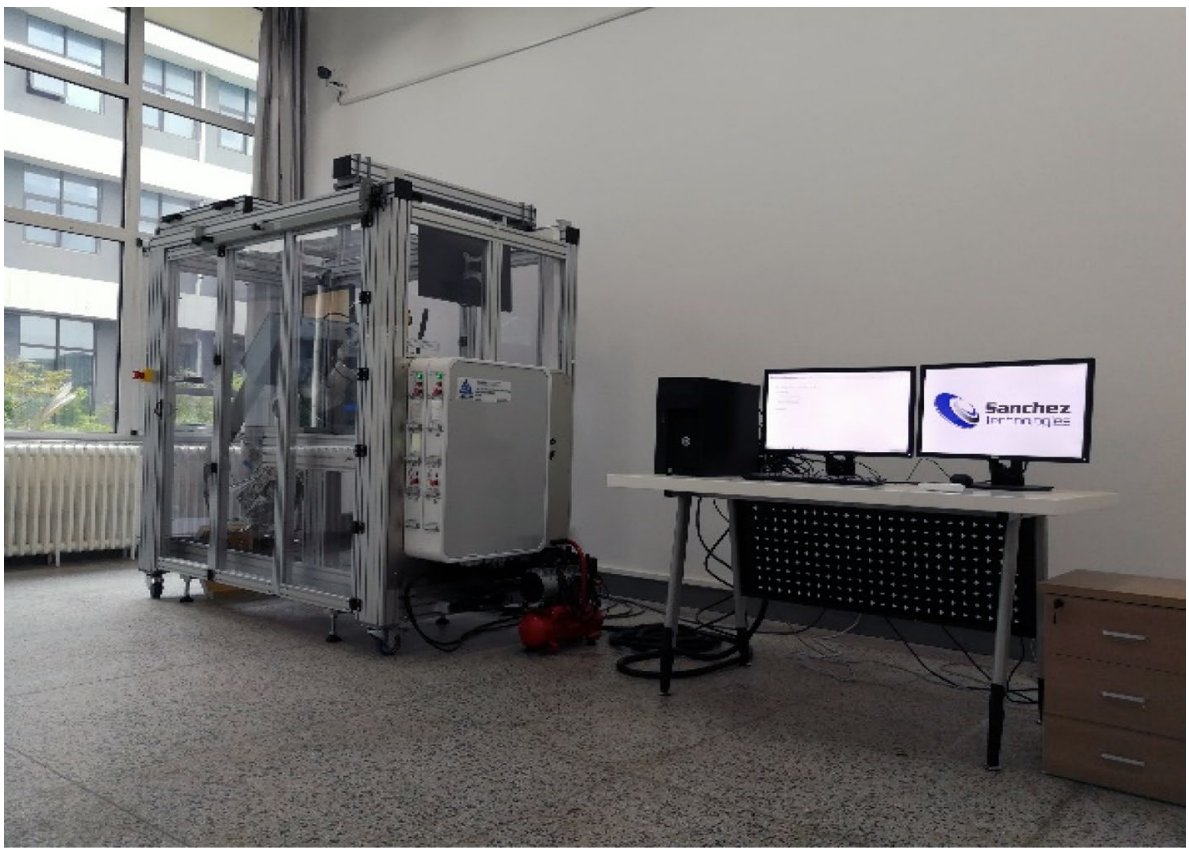

8. The GOR was changed to $4,8,12$, and 16 , and the (2)(7) experiment was repeated.

\section{Bubble point pressure test results}

When the GOR is 2 , the phase state change results of crude oil are shown in Fig. 2.

It can be seen from Fig. 2 that when the volume increases, the pressure first decreases rapidly and then decreases slowly. When the pressure is high, the fluid is in the liquid phase, the compressibility coefficient is small, and the pressure changes obviously with the volume. When the pressure drops to a specific value, the fluid becomes gas-liquid two-phase, the compression coefficient increases, and the pressure does not change obviously with the volume. At the same time, it can be seen that the curves of the three different depressurization modes do not wholly coincide. The bubble point pressure measured by balanced depressurization is $1.23 \mathrm{MPa}$, the bubble point pressure measured by rapid depressurization is $0.68 \mathrm{MPa}$, and the bubble point pressure measured by slow depressurization is $1.12 \mathrm{MPa}$. The faster the depressurization rate is, the gas dissolved in the crude oil would not have time to escape but exists in the crude oil in the form of bubbles, as shown in Fig. 3. Only when the pressure decreases to a certain value, the bubbles would escape forming gas. Therefore, the faster the pressure reduction speed is, the lower the bubble point pressure is.

When the GOR is 4 , the phase state change results of crude oil are shown in Fig. 4.

It can be seen from Fig. 4 that when the volume increases, the pressure first decreases rapidly and then decreases slowly. When the pressure is high, the fluid is in the liquid

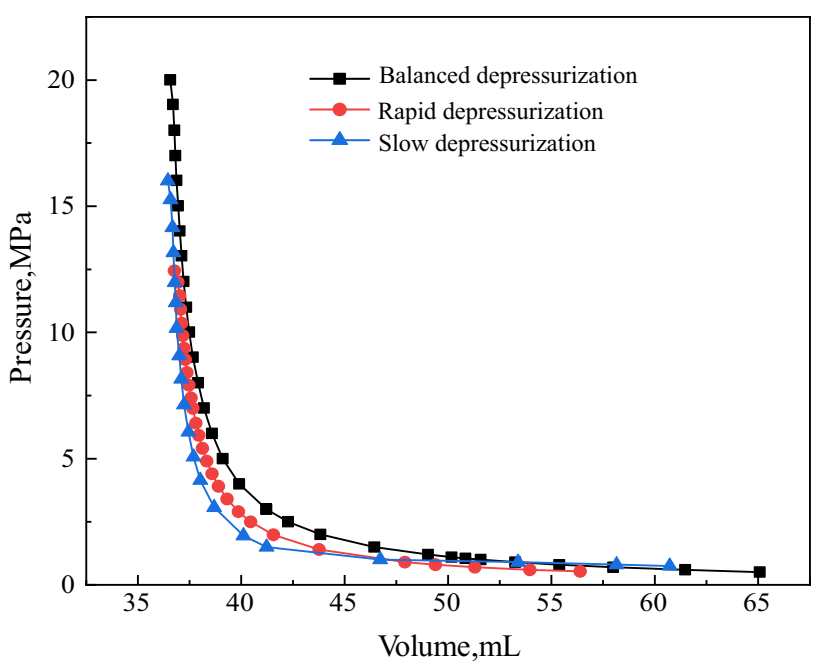

Fig. 2 Crude oil P-V curve with GOR of 2

phase, the compressibility coefficient is small, and the pressure changes obviously with the volume. When the pressure drops to a certain value, the fluid becomes gas-liquid twophase, the compression coefficient increases, and the pressure does not change obviously with the volume. At the same time, it can be seen that the curves of the three different depressurization modes do not wholly coincide. The bubble point pressure measured by balanced depressurization is $3.54 \mathrm{MPa}$, the bubble point pressure measured by rapid depressurization is $2.18 \mathrm{MPa}$, and the bubble point pressure measured by slow depressurization is $3.05 \mathrm{MPa}$. The faster the depressurization speed is, the lower the bubble point pressure is. 


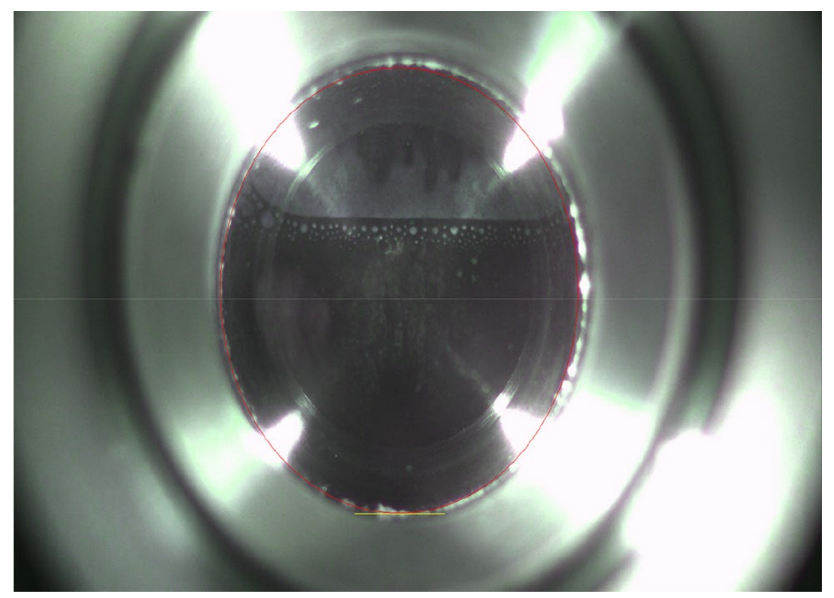

Fig. 3 Rapid depressurization liquid state of crude oil when GOR is 2

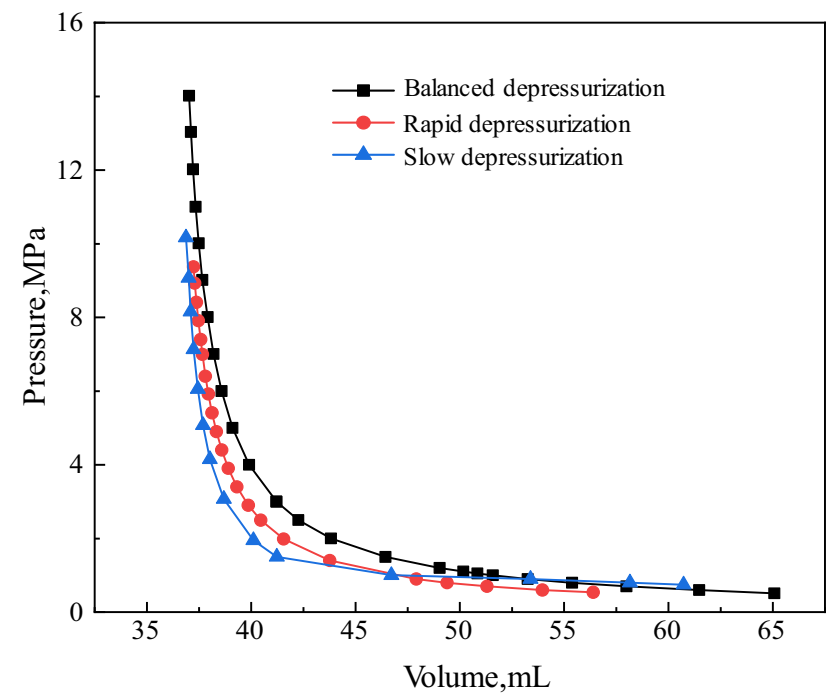

Fig. 4 P-V curve of crude oil when GOR is 4

When the GOR is 8 , the phase state change results of crude oil are shown in Fig. 5.

As shown in Fig. 5, when the volume increases, the pressure first decreases rapidly and then decreases slowly. When the pressure is high, the fluid is in the liquid phase, the compressibility coefficient is small, and the pressure changes obviously with the volume. When the pressure drops to a certain value, the fluid becomes gas-liquid two-phase, the compression coefficient increases, and the pressure does not change obviously with the volume. At the same time, it can be seen that the curves of the three different depressurization methods do not entirely coincide. The bubble point pressure measured by balanced depressurization is $5.15 \mathrm{MPa}$, the bubble point pressure measured by rapid depressurization is $3.63 \mathrm{MPa}$, and the bubble point pressure measured by slow depressurization

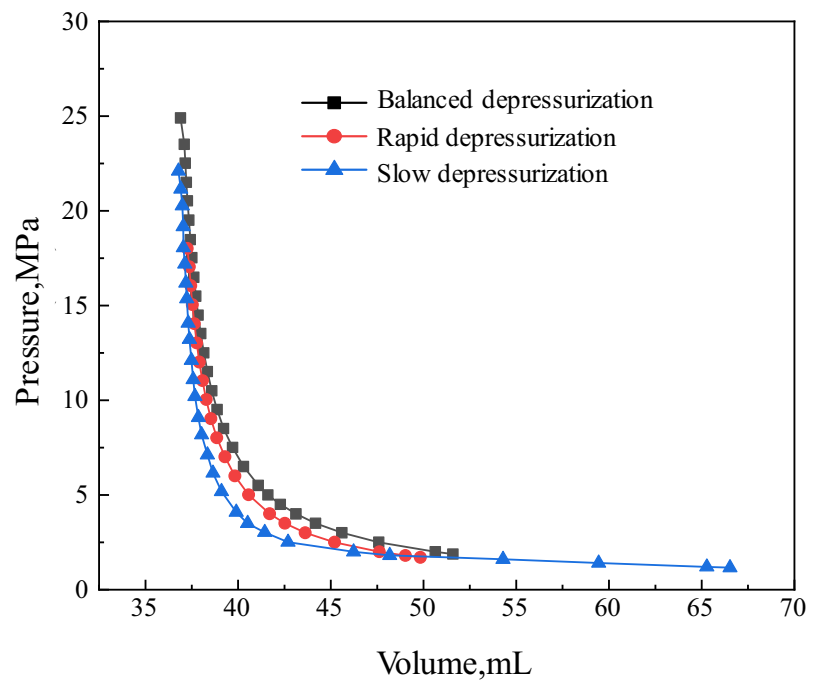

Fig. 5 Crude oil P-V curve when GOR is 8

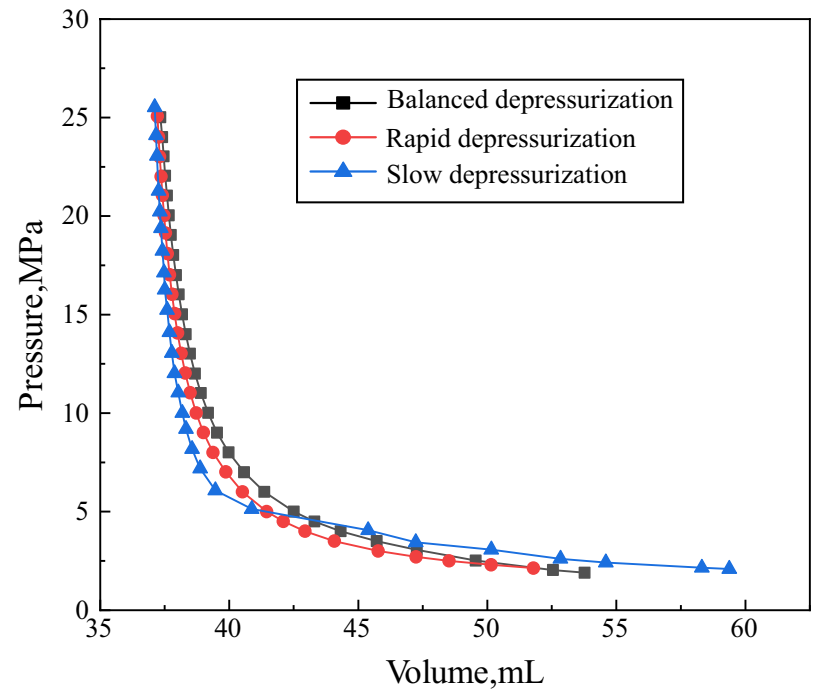

Fig. 6 P-V curve of crude oil when GOR is 12

is $4.65 \mathrm{MPa}$. The faster the depressurization speed is, the lower the bubble point pressure is.

When the GOR is 12, the phase state change results of crude oil are shown in Fig. 6.

It can be seen from Fig. 6 that when the volume increases, the pressure first decreases rapidly and then decreases slowly. When the pressure is high, the fluid is in the liquid phase, the compressibility coefficient is small, and the pressure changes obviously with the volume. When the pressure drops to a certain value, the fluid becomes gas-liquid two-phase, the compression coefficient increases, and the pressure does not change obviously with the volume. At the same time, it can be seen 
that the curves of the three different depressurization modes do not wholly coincide. The bubble point pressure measured by balanced depressurization is $6.02 \mathrm{MPa}$, the bubble point pressure measured by rapid depressurization is $5.44 \mathrm{MPa}$, and the bubble point pressure measured by slow depressurization is $5.71 \mathrm{MPa}$. The faster the depressurization speed is, the lower the bubble point pressure is.

When the GOR is 16 , the phase state change results of crude oil are shown in Fig. 7.

It can be seen from Fig. 7 that when the volume increases, the pressure first decreases rapidly and then decreases slowly. When the pressure is high, the fluid is in the liquid phase, the compressibility coefficient is small, and the pressure changes obviously with the volume. When the pressure drops to a certain value, the fluid becomes gas-liquid two-phase, the compression coefficient increases, and the pressure does not change obviously with the volume. At the same time, it can be seen that the curves of the three different depressurization modes do not wholly coincide. The bubble point pressure measured by balanced depressurization is $8.12 \mathrm{MPa}$, the bubble point pressure measured by rapid depressurization is $6.81 \mathrm{MPa}$, and the bubble point pressure measured by slow depressurization is $7.49 \mathrm{MPa}$. The faster the depressurization speed is, the lower the bubble point pressure is.

Figure 8 shows the solubility of the gas in crude oil under different pressures. It can be seen that the solubility of natural gas increases with the increase in pressure, which is approximately linear.

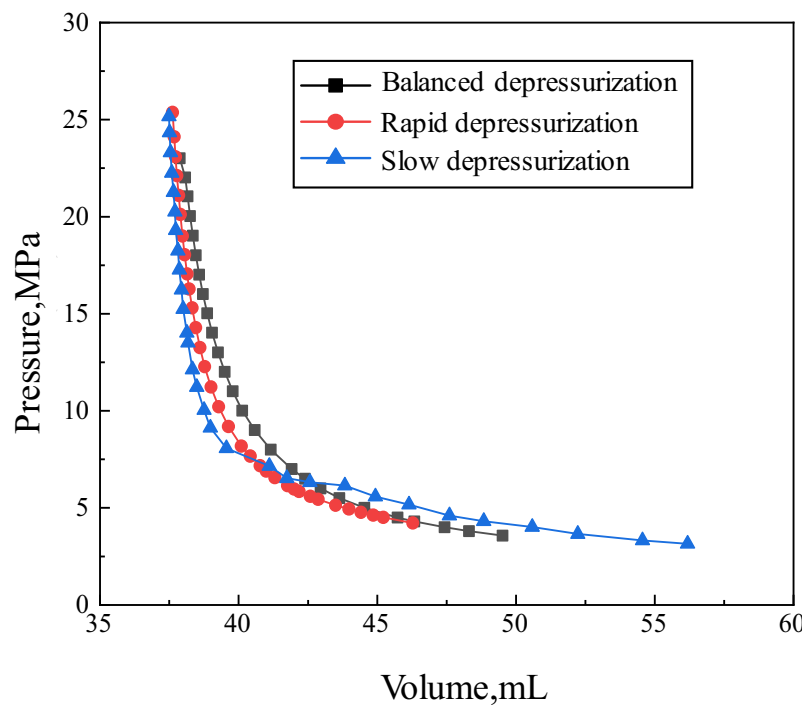

Fig. 7 P-V curve of crude oil with GOR of 16

\section{Summary}

According to the bubble point pressure experiment results, the larger the gas-oil ratio is, the greater the bubble point pressure is (see Table 2). The more dissolved gas, the greater the pressure required and the corresponding bubble point pressure. The faster the depressurization rate is, the gas dissolved in the crude oil would not have time to escape but exists in the crude oil in the form of bubbles. Only when the pressure decreases to a certain value, the bubbles would escape forming gas. Therefore, the faster the pressure reduction speed is, the lower the bubble point pressure is, as shown in Table 2. The faster the depressurization rate, the gas dissolved in the crude oil has no time to escape but exists in the crude oil in the form of bubbles. Only when the pressure decreases to a specific value, the bubbles would escape forming gas.

\section{Crude oil viscosity measurement}

Experimental instrument: falling ball viscometer, as shown in Fig. 9.

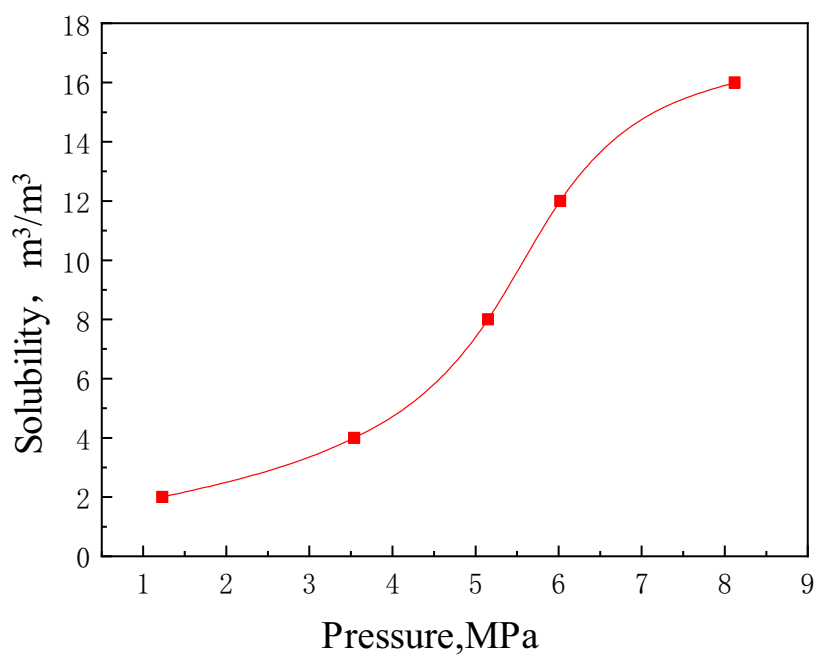

Fig. 8 Solubility curve of gas in crude oil

Table 2 Bubble point pressure under different pressure drop modes

\begin{tabular}{llllll}
\hline $\begin{array}{l}\text { Mode of pressure } \\
\text { drop }\end{array}$ & \multicolumn{5}{l}{ Bubble point pressure } \\
\cline { 2 - 6 } & GOR 2 & GOR 4 & GOR 8 & GOR 12 & GOR 16 \\
\hline $\begin{array}{l}\text { Balanced depressuri- } \\
\text { zation }\end{array}$ & 1.23 & 3.54 & 5.15 & 6.02 & 8.12 \\
$\begin{array}{l}\text { Rapid depressuriza- } \\
\text { tion }\end{array}$ & 0.69 & 2.18 & 3.63 & 5.44 & 6.81 \\
$\begin{array}{l}\text { Slow depressurization } \\
\text { lon }\end{array}$ & 1.12 & 3.05 & 4.65 & 5.71 & 7.49 \\
\hline
\end{tabular}


Fig. 9 Falling ball viscometer

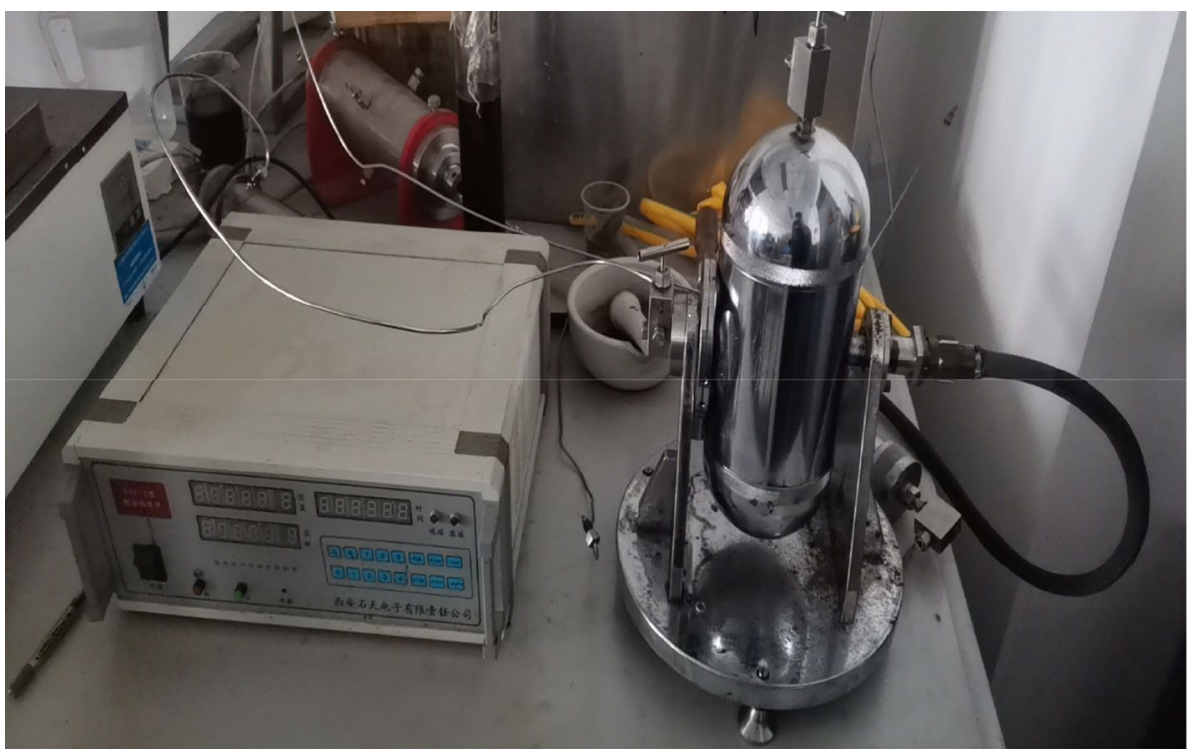

\section{Experimental steps:}

1. Transfer the standard solution GBW13608 to the standard tube of the falling ball viscometer, the temperature is $20{ }^{\circ} \mathrm{C}$, and the experimental angle is $90^{\circ}$;

2. Turn the falling ball viscometer so that the end (upper part) with the valve faces down, press the "ball suction" switch to make the steel ball suck onto the upper magnet;

3. Rotate the falling ball viscometer so that its upper part faces down and is fixed at a certain angle. Press the "drop ball" switch, the steel ball begins to fall, and the timing starts simultaneously. When the steel ball falls to the bottom, it would automatically stop timing and record the falling time of the steel ball. Repeat more than 3 times until the measured time is the same;

4. Replace standard solutions GBW13609 and GBW13611, repeat (2) (3);

5. Take the viscosity value of the three standard solutions as the ordinate $\left(\rho_{\text {ball }}-\rho_{\text {liquid }}\right) t$ is the abscissa, draw the points of each angle in the coordinate system, and the slope is the viscometer constant $\mathrm{K}$;

6. After the oil sample is prepared according to the GOR of 4 , transfer it to the standard tube of the falling ball viscometer, control the pressure at $15 \mathrm{MPa}$, repeat (2)-(3), and measure the viscosity at $65{ }^{\circ} \mathrm{C}, 75{ }^{\circ} \mathrm{C}, 85^{\circ} \mathrm{C}, 95{ }^{\circ} \mathrm{C}$ and $105{ }^{\circ} \mathrm{C}$, respectively;

7. Change the GOR to 8 and 16 and repeat the experiment (5).
Table 3 Standard solution parameters

\begin{tabular}{lllll}
\hline $\begin{array}{l}\text { Name of } \\
\text { standard solu- } \\
\text { tion }\end{array}$ & $\begin{array}{l}\text { Tempera- } \\
\text { ture }\left({ }^{\circ} \mathrm{C}\right)\end{array}$ & Angle $\left(^{\circ}\right)$ & $\begin{array}{l}\text { Dynamic } \\
\text { viscosity } \\
(\mathrm{mPa} \mathrm{s})\end{array}$ & Density $\left(\mathrm{cm}^{3}\right)$ \\
\hline GBW13608 & 20 & 90 & 538.34 & 0.9726 \\
GBW13609 & 20 & 90 & 955.21 & 0.9729 \\
GBW13611 & 20 & 90 & 4827.50 & 0.9715 \\
\hline
\end{tabular}

\section{Experimental result}

The parameters of the standard solution used in the experiment are shown in Table 3. The calibration results are shown in Fig. 10. It can be seen that after calibration with the standard solution, the calibration curve is approximately a straight line. When the falling angle of the falling ball viscometer is $90^{\circ}$, the viscometer constant of the curve is 1.4676 .

The variation of crude oil with GOR and temperature is shown in Fig. 11. It can be seen from Fig. 11 that under the same GOR, the crude oil viscosity first decreases rapidly with the increase in temperature and then decreases slowly when the temperature is higher than $85{ }^{\circ} \mathrm{C}$, indicating that the crude oil viscosity is sensitive to temperature. At the same temperature, the crude oil viscosity decreases with the increase in GOR.

The experiment shows bubbles in crude oil, showing the "foam oil" phenomenon, as shown in Fig. 12. 


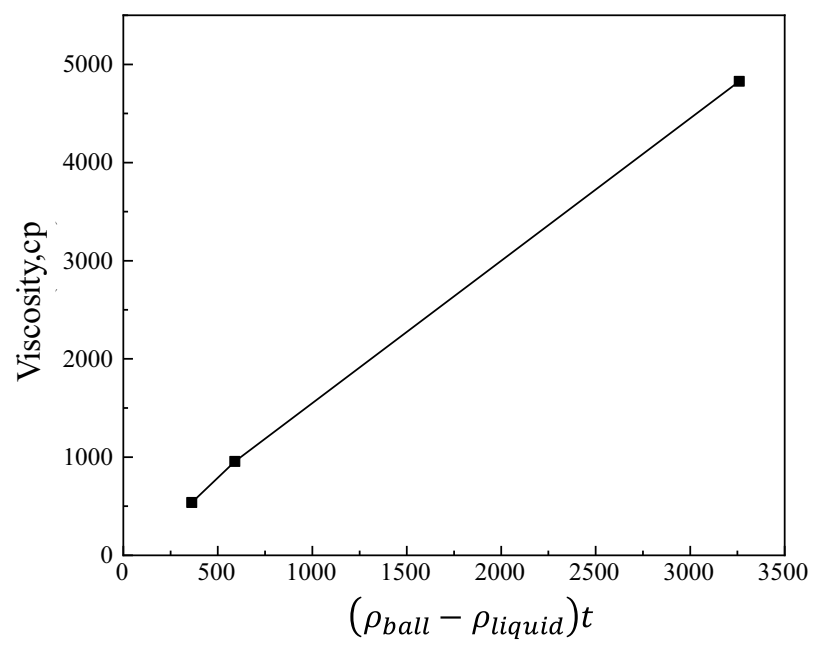

Fig. 10 Calibration curve of standard solution

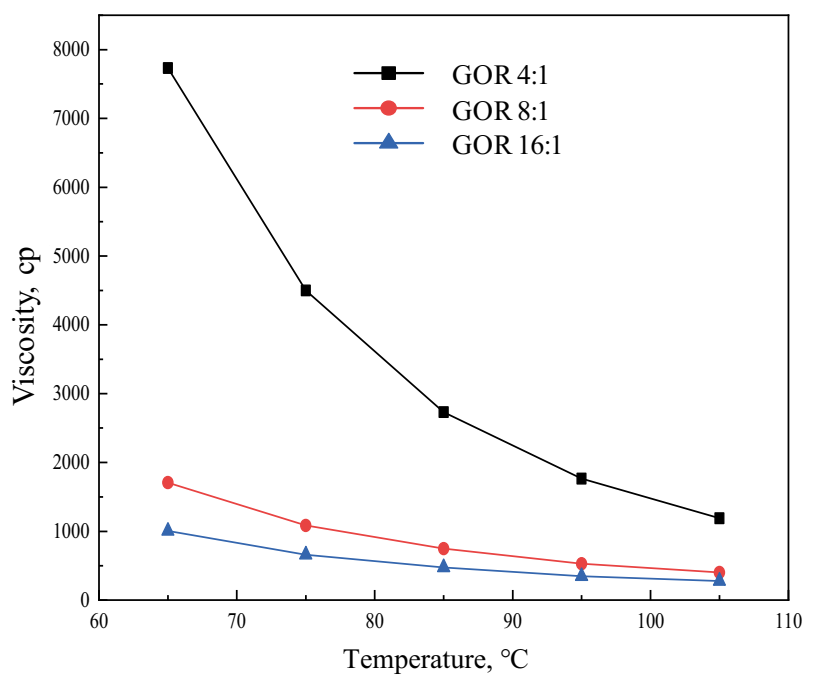

Fig. 11 Variation curve of crude oil viscosity with temperature

\section{Viscosity-temperature test}

Experimental material: Degassed crude oil. Experiment method

1. Put a certain volume of crude oil into the crude oil electric dehydrator, as shown in Fig. 13, set the temperature of the dehydrator to $105^{\circ} \mathrm{C}$ and dehydrate for $24 \mathrm{~h}$;

2. Take a certain amount of dehydrated crude oil and put it into the MCR302 ANTONPA rheometer. As shown in Fig. 14, heat the crude oil to the target experimental temperature and measure the crude oil viscosity at different shear rates;
3. Change the temperature and measure the crude oil viscosity at different temperatures. The temperature range is $40-110{ }^{\circ} \mathrm{C}$.

Experiment result

The viscosity of dehydrated crude oil at different temperatures and shear rates is measured, and the results are shown in Figs. 15 and 16.

It can be seen from Fig. 15 that at the same temperature, the viscosity of crude oil decreases with the increase in shear rate, showing the characteristics of shear thinning. At the formation temperature of $65^{\circ} \mathrm{C}$, with the increase in shear rate, the crude oil viscosity decreases from 3250 to $1660 \mathrm{cp}$. Figure 16 shows the crude oil viscosity at different temperatures at the same shear rate. It can be seen that the crude oil viscosity first decreases rapidly with the increase in temperature, from 9340 to $724 \mathrm{cp}$. When the temperature is higher than $80{ }^{\circ} \mathrm{C}$, the reduction range of crude oil viscosity decreases.

\section{Rheological test}

Experimental materials: Degassed crude oil, methane, and ethane.

Experimental instruments: High temperature and highpressure capillary viscosity measuring device and crude oil sampler, as shown in Fig. 17.

Experimental Objective: Analyze the viscosity characteristics of heavy oil at different temperatures and pressures and determine its influencing factors.

Experiment content

1. Crude oil viscosity at different temperatures;

2. Viscosity of crude oil at different shear rates;

3. Crude oil viscosity under different dissolved GOR.

Prepare live oil according to the GOR. The test steps of live oil viscosity are as follows:

1. Prepare live oil under a certain saturation pressure;

2. Set the temperature of the incubator to the test temperature $\left(65^{\circ} \mathrm{C}\right)$, keep it constant for $4 \mathrm{~h}$, and place the prepared live oil in the sample cylinder;

3. Adjust the pressure of the backpressure valve to the saturation pressure, set the pump flow rate to $0.2 \mathrm{~mL} / \mathrm{min}$ and $0.5 \mathrm{~mL} / \mathrm{min}$, respectively, test the stable differential pressure at both ends of the capillary at different temperatures $\left(65{ }^{\circ} \mathrm{C}, 75{ }^{\circ} \mathrm{C}, 85^{\circ} \mathrm{C}, 95^{\circ} \mathrm{C}\right.$, and $\left.105{ }^{\circ} \mathrm{C}\right)$ from low to high, measure the gas content in the crude oil and accurately measure the GOR;

4. Prepare live oil under different saturation pressures and repeat steps (2) and (3) to obtain the relationship

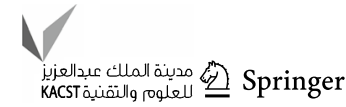


Fig. 12 Foam oil phenomenon photos

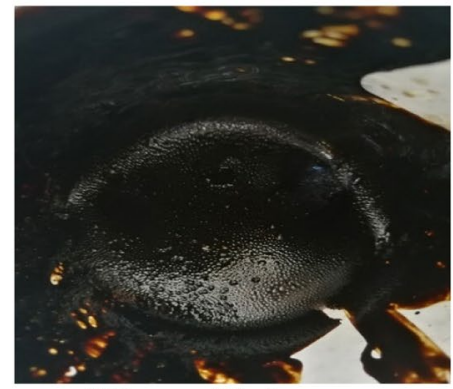

(a) export of "foam oil" phenomenon

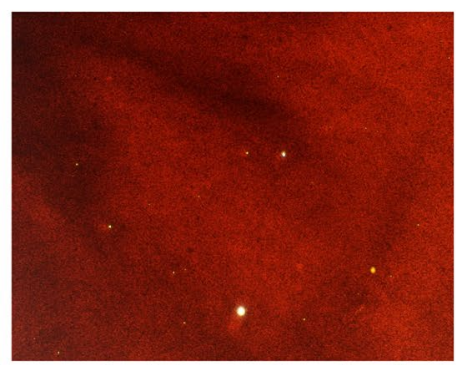

(c) Micrograph of degassed crude oil at 40x magnification

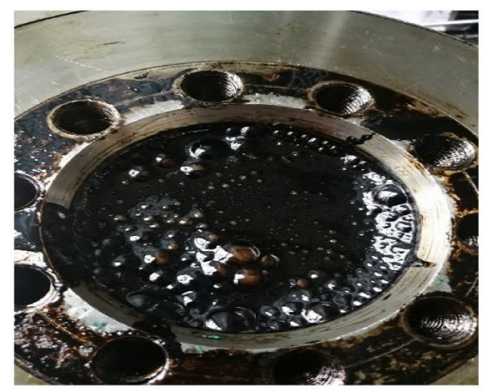

(b) the phenomenon of crude oil depressurization "foam oil" in the distributor.

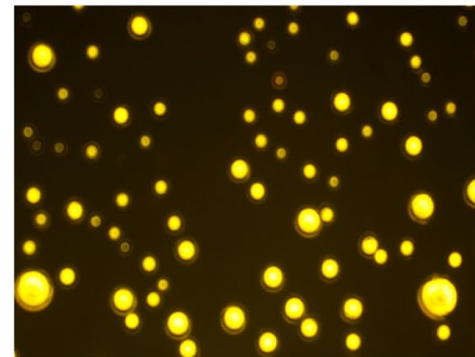

(d) Micrograph of gas-bearing crude oil, enlarged by 40 times

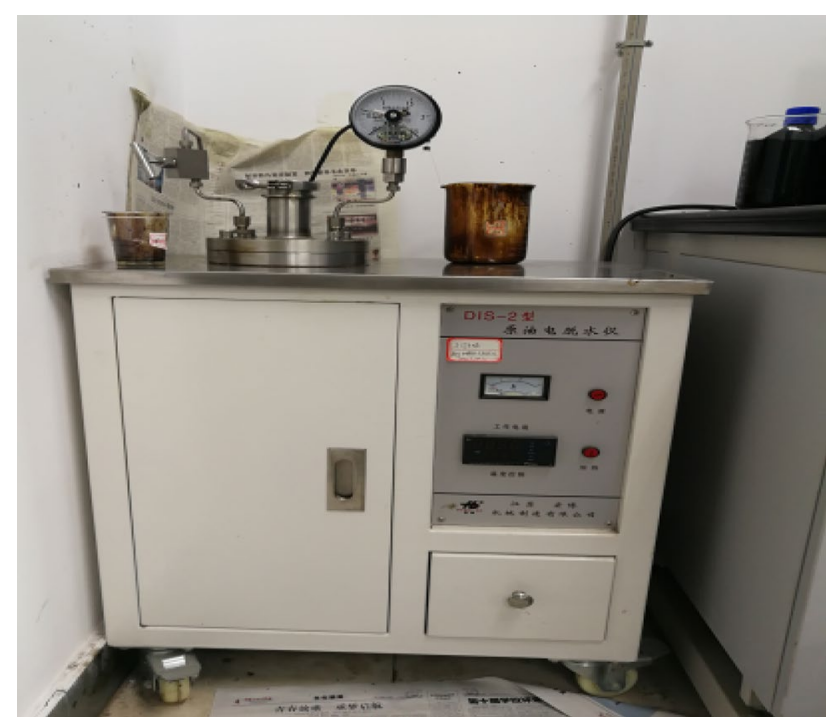

Fig. 13 Crude oil dehydrator

between capillary stable differential pressure and flow rate to obtain the viscosity of live oil.

In the degassing crude oil rheology experiment, the thermostat's temperature is set to the test temperature and constant temperature $4 \mathrm{~h}$. The degassing crude oil is used as the oil sample tube; then, the pressure of the return valve is adjusted to the test pressure. The relationship between the capillary pressure and the flow rate under different flow rates $(1 \mathrm{~mL} / \mathrm{min}, 2 \mathrm{~mL} / \mathrm{min}, 3 \mathrm{~mL} / \mathrm{min}, 4 \mathrm{~mL} / \mathrm{min})$ and pressure is tested, and the viscosity of degassing crude oil is obtained.

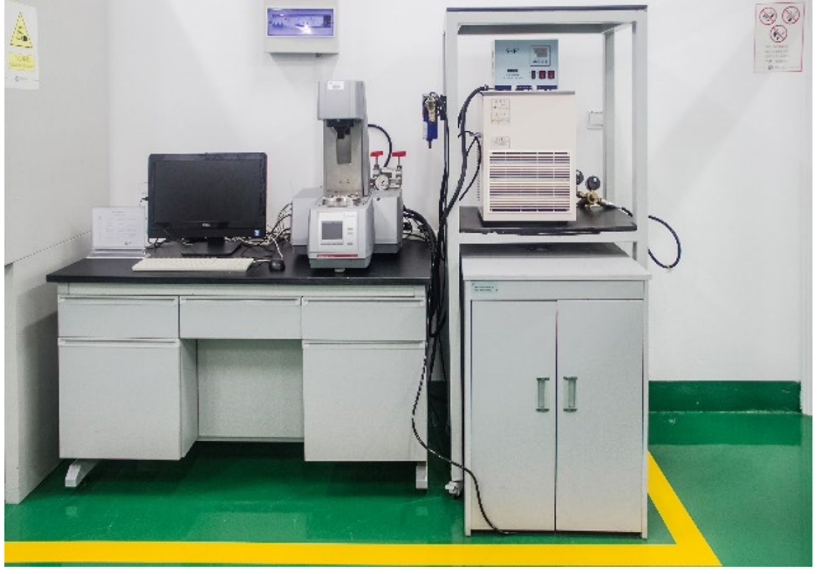

Fig. 14 MCR302 ANTONPA rheometer

Experiment results

Through the thin tube viscosity measuring device, the change of crude oil viscosity measured when the GOR is 4 is shown in Fig. 18.

It can be seen from Fig. 18 that when the GOR is 4 , the speed is $0.2 \mathrm{~mL} / \mathrm{min}$, the viscosity is between 3540 and $991 \mathrm{cp}$, the speed is $0.5 \mathrm{~mL} / \mathrm{min}$, the viscosity is between 2815 and $226 \mathrm{cp}$, the temperature increases, the viscosity decreases, the shear rate increases, the viscosity decreases, the temperature is higher than about $85^{\circ} \mathrm{C}$, and the decreasing amplitude of viscosity decreases with the increase in temperature. 


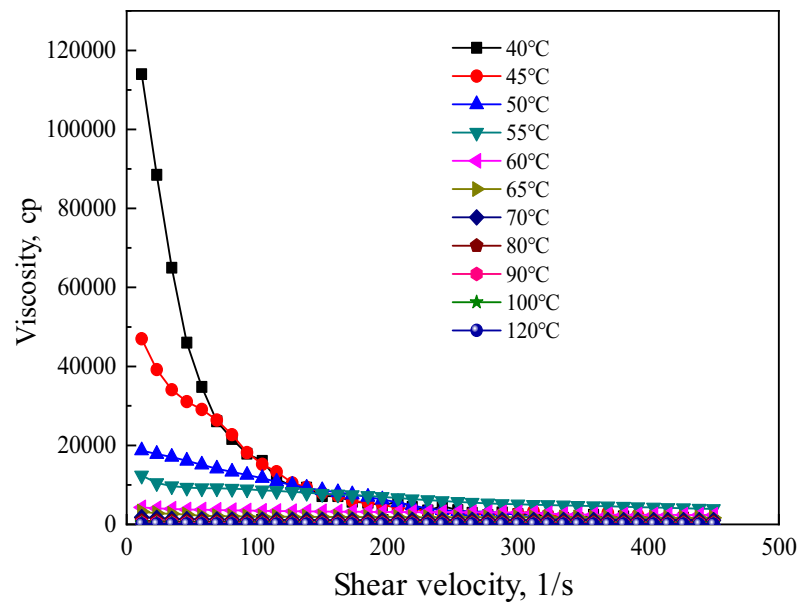

Fig. 15 Viscosity-temperature curve of crude oil

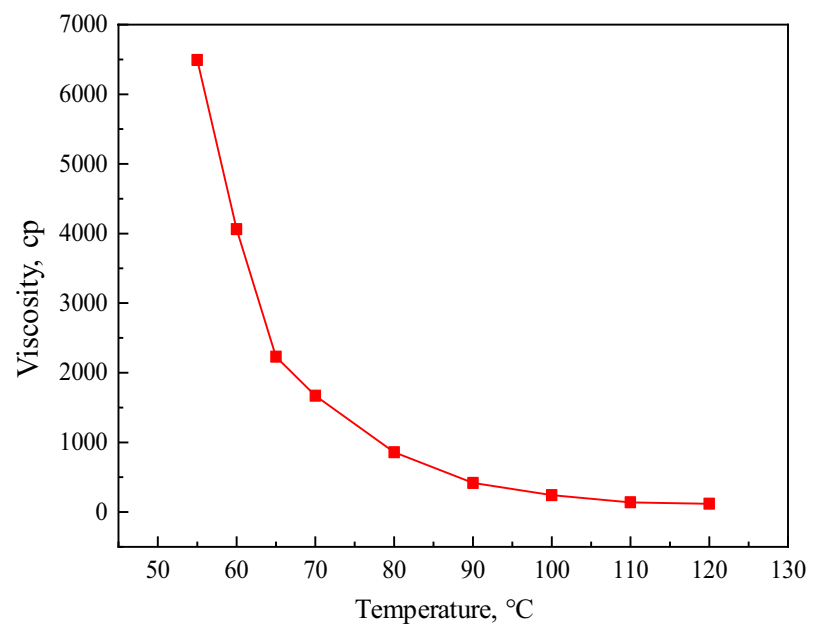

Fig. 16 Variation of crude oil viscosity with temperature

Through the thin tube viscosity measuring device, the change of crude oil viscosity measured when the GOR is 6 is shown in Fig. 19.

It can be seen from Fig. 16 that when the GOR is 6 , the speed is $0.2 \mathrm{~mL} / \mathrm{min}$, the viscosity is between 3369 and $240 \mathrm{cp}$, the speed is $0.5 \mathrm{~mL} / \mathrm{min}$, the viscosity is between 2768 and $140 \mathrm{cp}$, the temperature increases, the viscosity decreases, the shear rate increases, the viscosity decreases, the temperature is higher than about $85^{\circ} \mathrm{C}$, and the decreased amplitude of viscosity decreases with the increase in temperature.

Through the thin tube viscosity measuring device, the change of crude oil viscosity measured when the GOR is 12 is shown in Fig. 20.

As shown in Fig. 20, when the GOR is 12, the speed is $0.2 \mathrm{~mL} / \mathrm{min}$. The viscosity is between 2719 and $220 \mathrm{cp}$.
The speed is $0.5 \mathrm{~mL} / \mathrm{min}$. The viscosity is between 1647 and $126 \mathrm{cp}$, the temperature increases, the viscosity decreases, the shear rate increases, and the viscosity decreases. When the temperature is higher than $85^{\circ} \mathrm{C}$, the viscosity decreases with the increase in temperature.

Figure 21 shows the viscosity of degassed crude oil and crude oil with the GOR of 30 under different shear rates. The viscosity of gas containing crude oil is $258-377 \mathrm{cp}$, significantly lower than that of degassed crude oil under the same conditions.

\section{Summary}

The viscosity-temperature test shows that the viscosity of crude oil decreases with the increase in shear rate at the same temperature, showing the characteristics of shear thinning. With the increase in temperature, the crude oil viscosity first decreases rapidly. When the temperature is higher than $80{ }^{\circ} \mathrm{C}$, the decrease range of crude oil viscosity decreases.

\section{Core seepage characteristic test}

Experimental materials: Degassed crude oil, methane, and ethane; Quartz sand.

Experiment method

By measuring the pressure difference of stable seepage of crude oil in sand-filled pipe, the seepage characteristics of crude oil are analyzed. The main experimental steps are as follows:

1. Wash the two cores sampled on-site, as shown in Fig. 22. Measure the basic parameters after oil washing, as shown in Table 4, Then measure the water permeability and gas permeability, respectively, and the results are shown in Tables 5 and 6 . It can be seen that the gas logging permeability is $2-3$ times that of the liquid logging permeability, and the formation gas logging permeability is $3000 \mathrm{mD}$, so the liquid logging permeability of the sand filling pipe should be $1000-1500 \mathrm{mD}$.

2. Wash the formation sand. The comparison before and after oil washing is shown in Fig. 23. The laser particle size analyzer is used for particle size analysis. The analysis results are shown in Table 7.

3. Fill the sand filling the pipe with the particle size combination shown in Table 7, and then vacuum the saturated kerosene to determine the porosity and permeability.

4. Inject the crude oil into the sand filling pipe. Keep the backpressure higher than the bubble point pressure to avoid crude oil degassing during the injection process.

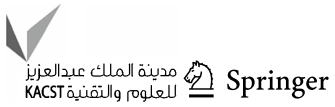


Fig. 17 High temperature and high-pressure capillary viscosity measuring device

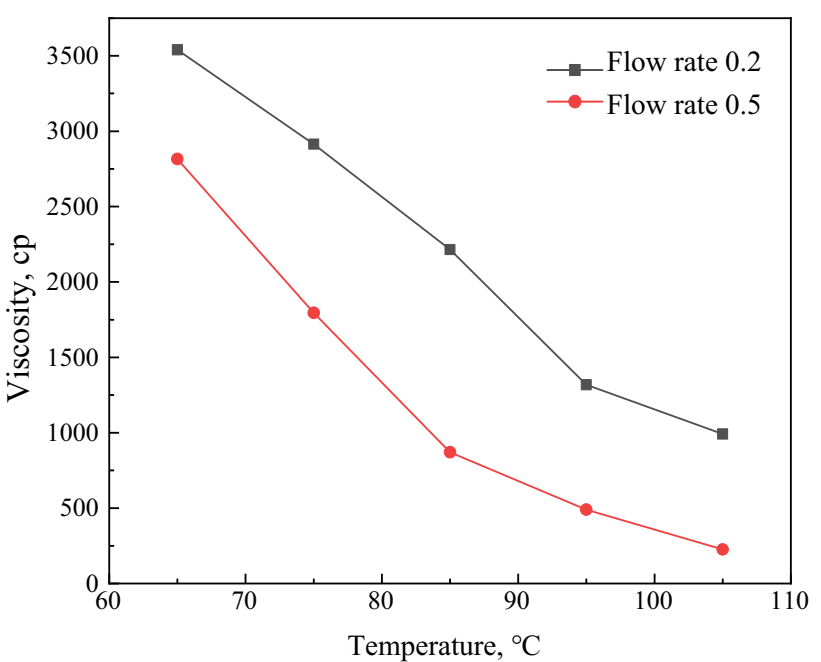

Fig. 18 Viscosity of crude oil with GOR of 4

Measure the outlet GOR. When the outlet GOR is equal to the GOR of the injected crude oil, continue to inject $1 \mathrm{PV}$.

5. The temperature is set at $65{ }^{\circ} \mathrm{C}$. After the sand filling pipe is aged $24 \mathrm{~h}$, set different injection speeds and conduct a seepage experiment. After each injection speed is stable, measure the differential pressure at both ends of the sand filling pipe, and proceed to the next speed.

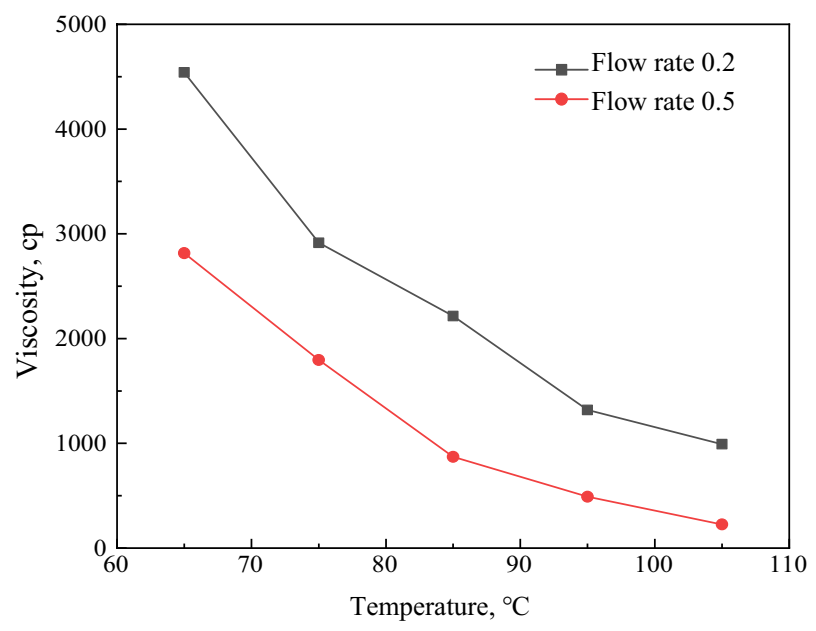

Fig. 19 Viscosity of crude oil with GOR of 6

6. Draw the relationship curve between differential pressure and injection velocity, and analyze the characteristics of crude oil seepage.

\section{Experiment result}

The percolation characteristics of formation crude oil at different temperatures are tested.

(1) Seepage characteristics at $65^{\circ} \mathrm{C}$

The seepage characteristics at the formation temperature of $65^{\circ} \mathrm{C}$ are shown in Fig. 24. It can be seen that when the 


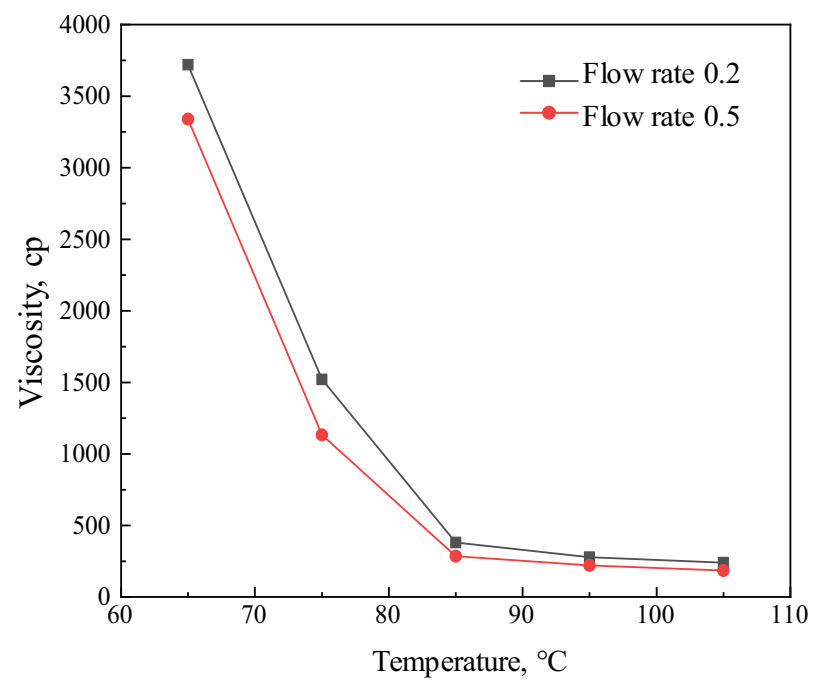

Fig. 20 Viscosity of crude oil with GOR of 12

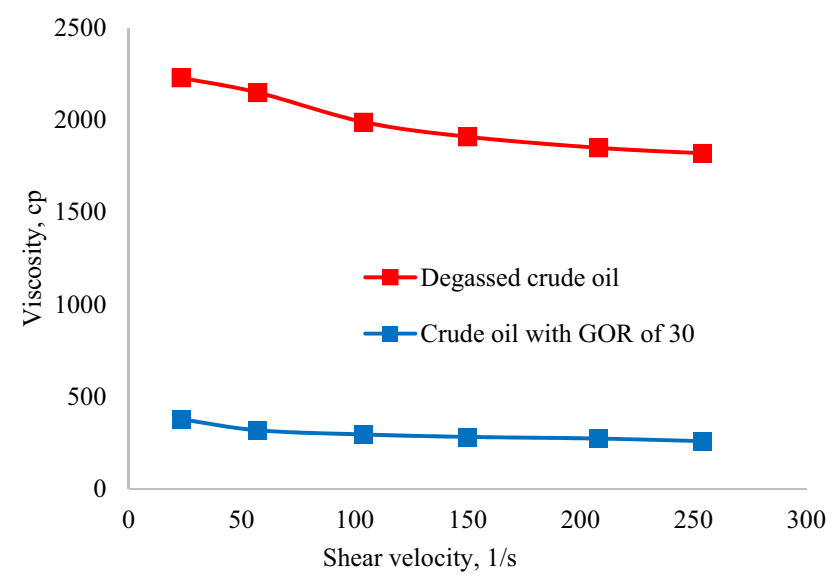

Fig. 21 Viscosity of degassed crude oil and crude oil with GOR of 30 under different shear rates

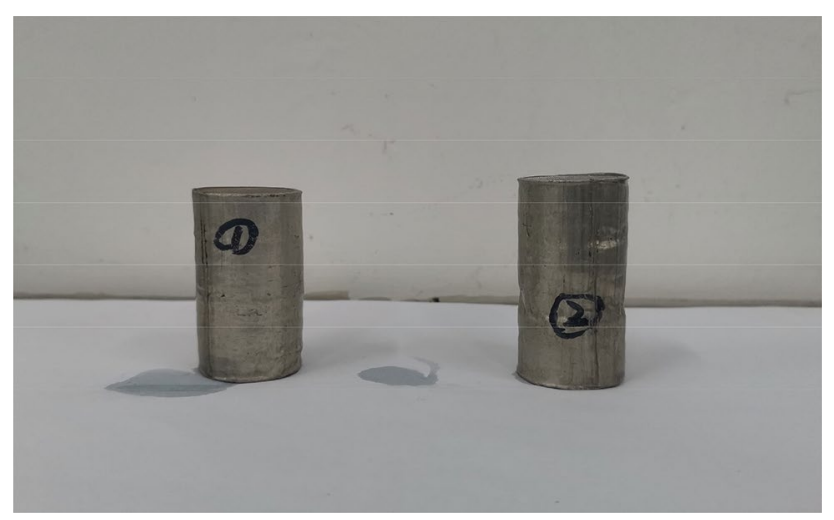

Fig. 22 Core 1 (left), core 2 (right) pressure gradient is small, the seepage velocity increases slowly with the increase in the pressure gradient. A curve relationship between seepage velocity and pressure gradient indicates that oil seepage would occur under a small pressure gradient. However, in this case, the seepage velocity is much smaller than that under Darcy's law. With the increase in pressure gradient, the seepage velocity also increases. When the pressure gradient reaches a certain value, the seepage velocity and pressure gradient gradually become linear.

Figure 24 shows the relationship between viscosity and flow rate. It can be seen that with the increase in flow rate, the viscosity decreases from 1125 to $349 \mathrm{cp}$, first decreases rapidly and then tends to be flat, which is approximately a power function, showing the characteristics of shear thinning. When the output of well c $44 \mathrm{~h} 1$ is $50-70 \mathrm{~m}^{3} / \mathrm{day}$, according to Fig. 24, the viscosity is $600-730 \mathrm{cp}$.

\section{(2) Seepage characteristics at $95{ }^{\circ} \mathrm{C}$}

The seepage characteristics at the formation temperature of $95{ }^{\circ} \mathrm{C}$ are shown in Fig. 25.

It can be seen that similar to the results at $65^{\circ} \mathrm{C}$, when the pressure gradient is small, the seepage velocity increases slowly with the pressure gradient increase. The relationship between the seepage velocity and the pressure gradient is a curve of the concave velocity axis, which indicates that oil seepage would occur under a small pressure gradient. However, in this case, the seepage velocity is much smaller than that under Darcy's law. With the increase in pressure gradient, the seepage velocity also increases. When the pressure gradient reaches a certain value, the seepage velocity and pressure gradient gradually become linear.

Figure 25 shows the relationship between viscosity and flow rate. It can be seen that with the increase in flow rate, the viscosity decreases from 450 to $112 \mathrm{cp}$, which is approximately a power function, showing the characteristics of shear thinning. At the same time, the viscosity at $95{ }^{\circ} \mathrm{C}$ is lower than that at $65{ }^{\circ} \mathrm{C}$.

\section{(3) Seepage characteristics at $110{ }^{\circ} \mathrm{C}$}

The seepage characteristics at formation temperature of $110{ }^{\circ} \mathrm{C}$ are shown in Fig. 26. It can be seen that the relationship between velocity and pressure gradient is approximately linear, and the characteristics of non-Newtonian fluid are not prominent.

From Fig. 26, the crude oil viscosity first decreases rapidly with speed and then tends to be flat, ranging from 45 to $135 \mathrm{cp}$. 
Table 4 Basic parameters of rock samples

\begin{tabular}{lllllllll}
\hline Sample no & Radius (mm) & High (mm) & $\begin{array}{l}\text { Cross- } \\
\text { sectional area } \\
\left(\mathrm{mm}^{2}\right)\end{array}$ & Volume $\left(\mathrm{mm}^{3}\right)$ & $\begin{array}{l}\text { Quality (before } \\
\text { oil washing) }(\mathrm{g})\end{array}$ & $\begin{array}{l}\text { Quality (after } \\
\text { oil washing) }(\mathrm{g})\end{array}$ & $\begin{array}{l}\text { Quality (satu- } \\
\text { rated water) }(\mathrm{g})\end{array}$ & $\begin{array}{l}\text { Porosity (\%) } \\
\text { Core 1 }\end{array}$ \\
\hline Core 2 & 25.16 & 50.92 & 496.96 & $25,303.43$ & 50.44 & 47.86 & 54.99 & 28.18 \\
\hline
\end{tabular}

Table 5 Results of liquid permeability of core 1

\begin{tabular}{lllll}
\hline Permeability $(\mathrm{mD})$ & 1 & 2 & 3 & Average value \\
\hline Liquid permeability & 243 & 284 & 244 & 257 \\
Gas permeability & 562 & 541 & 562 & 555 \\
\hline
\end{tabular}

Table 6 Liquid permeability test results of core 2

\begin{tabular}{lllll}
\hline Permeability $(\mathrm{mD})$ & 1 & 2 & 3 & Average value \\
\hline Liquid permeability & 305 & 343 & 366 & 338 \\
Gas permeability & 916 & 959 & 930 & 935 \\
\hline
\end{tabular}

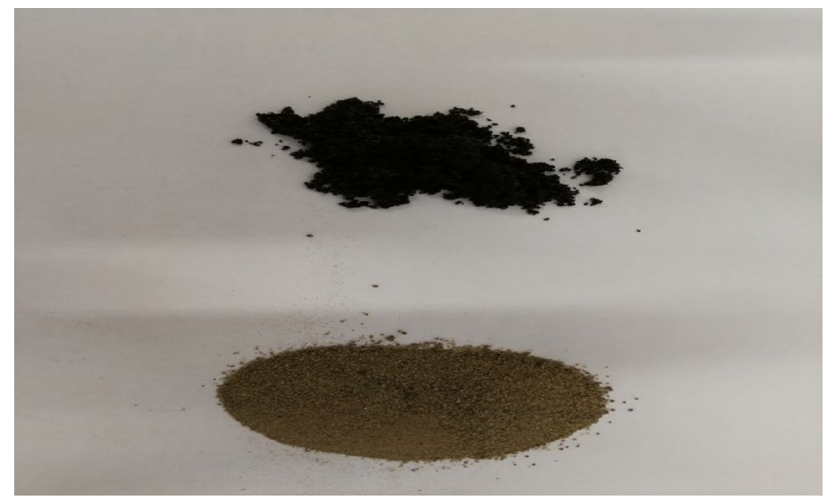

Fig. 23 Comparison of formation sand before (upper) and after (lower) oil washing

Table 7 Sand ratio for sand filling pipe

\begin{tabular}{llll}
\hline Mesh number & $40-80$ & $80-120$ & $120-180$ \\
Proportion (\%) & 65 & 20 & 15 \\
\hline
\end{tabular}

\section{(4) Seepage characteristics at $55^{\circ} \mathrm{C}$}

The relationship between flow rate and pressure gradient at $55{ }^{\circ} \mathrm{C}$ is shown in Fig. 27. Within the range of experimental flow rate, the relationship between flow rate and pressure gradient is approximately linear. The viscosity at this temperature is shown in Fig. 33. The viscosity first decreases rapidly and then decreases slowly with the increase in flow rate. When the production of well $\mathrm{c} 44 \mathrm{~h} 1$ is $50-70 \mathrm{~m}^{3} / \mathrm{day}$

ay, the viscosity is $2400-3400 \mathrm{cp}$, according to Fig. 33 .

According to the above experimental results, the relationship between crude oil viscosity and flow rate is approximately a power function at the same temperature. With the flow rate increase, the crude oil viscosity first decreases rapidly and then tends to be stable. With the increase in temperature, the viscosity of crude oil decreases, and the non-Newtonian characteristics weaken.

Table 8 shows the relationship between crude oil viscosity and seepage velocity at different temperatures.

\section{Summary}

The percolation experiment of crude oil core shows that when the temperature is $65{ }^{\circ} \mathrm{C}$ and $95{ }^{\circ} \mathrm{C}$, and the pressure gradient is small, the percolation velocity increases slowly with the increase in pressure gradient, and the relationship between percolation velocity and pressure gradient is a curve of concave velocity axis. With the increase in pressure gradient, the seepage velocity increases. When the pressure gradient reaches a certain value, the seepage velocity and pressure gradient gradually become linear. When the temperature is $110{ }^{\circ} \mathrm{C}$, the seepage velocity is approximately linear with the pressure gradient. With the increase in seepage velocity, the crude oil viscosity first decreases rapidly and then tends to be flat, forming a power function relationship. The crude oil viscosity ranges from 600 to $730 \mathrm{cp}$ at the formation temperature of $65^{\circ} \mathrm{C}$.

\section{Summary of crude oil properties}

1. The crude oil PVT experiment shows that the bubble point pressure is related to the pressure drop speed. The faster the pressure drop, the lower the bubble point pressure, showing the characteristics of the foaming oil, and the foam oil phenomenon is observed in the PVT tube. The bubble point pressure of crude oil under formation conditions is $3.54 \mathrm{MPa}$. 


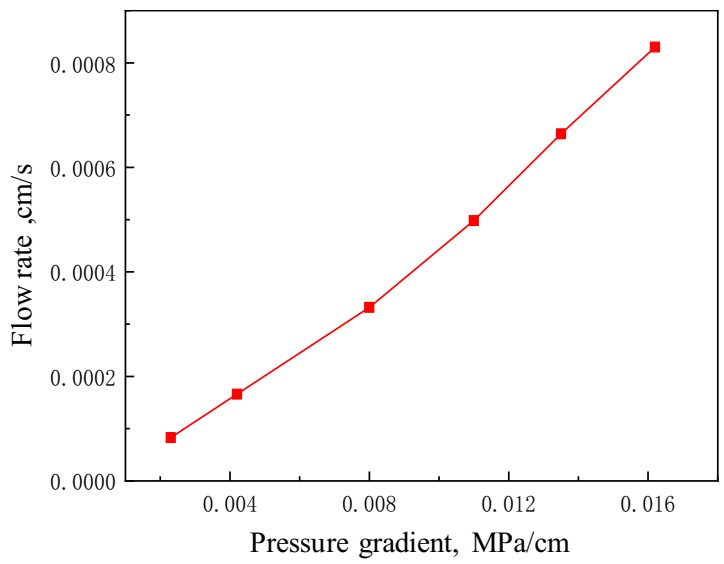

a relationship between flow velocity and pressure gradient at $65{ }^{\circ} \mathrm{C}$ (local)

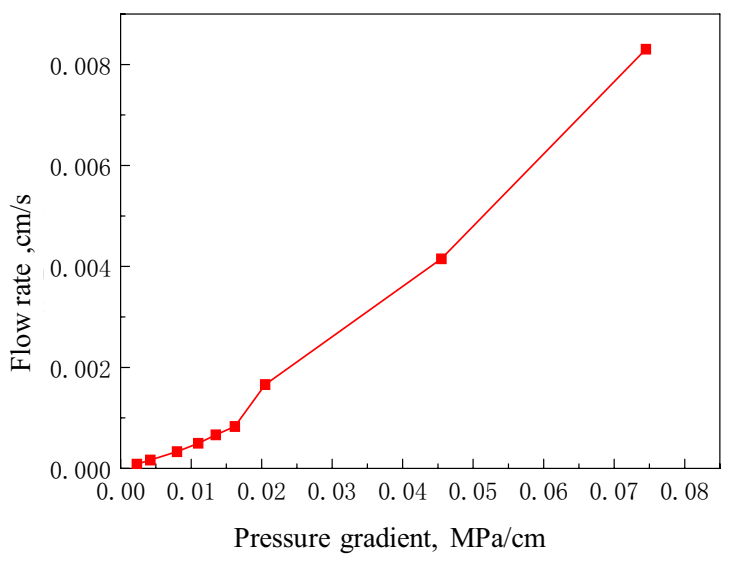

b Relationship between velocity and pressure gradient at $65{ }^{\circ} \mathrm{C}$

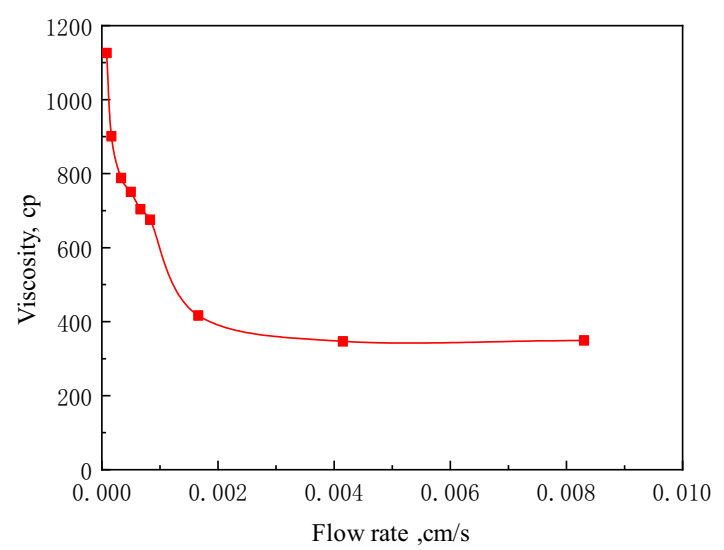

c Relationship between viscosity and pressure gradient at $65{ }^{\circ} \mathrm{C}$

Fig. 24 Seepage characteristics at $65^{\circ} \mathrm{C}$

2. The falling ball viscometer experiment shows that the higher the GOR of crude oil, the lower the crude oil viscosity. When the GOR is greater than 9, the viscosity decreases slowly. The viscosity of crude oil is sensitive to temperature and decreases rapidly with the

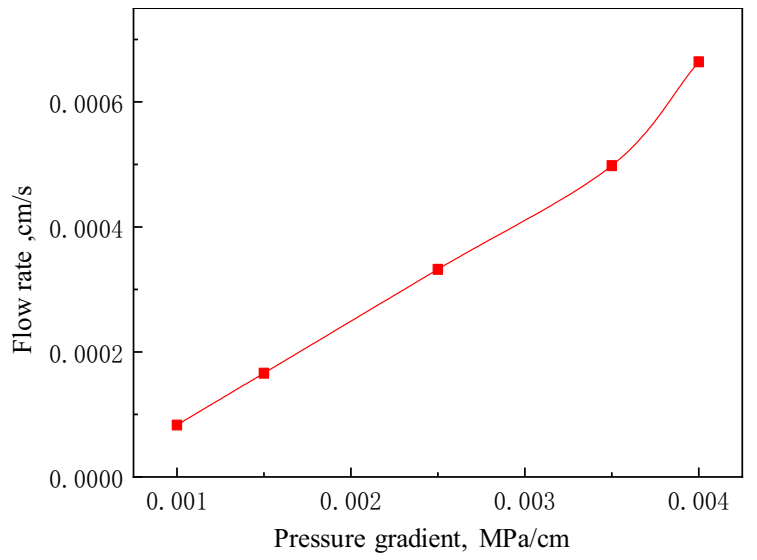

a relationship between flow velocity and pressure gradient at $95{ }^{\circ} \mathrm{C}$ (local)

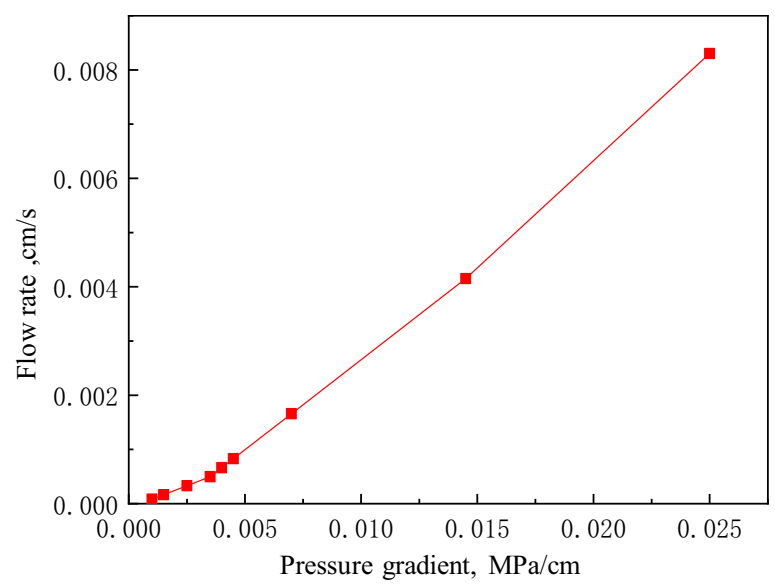

b Relationship between velocity and pressure gradient at $95{ }^{\circ} \mathrm{C}$

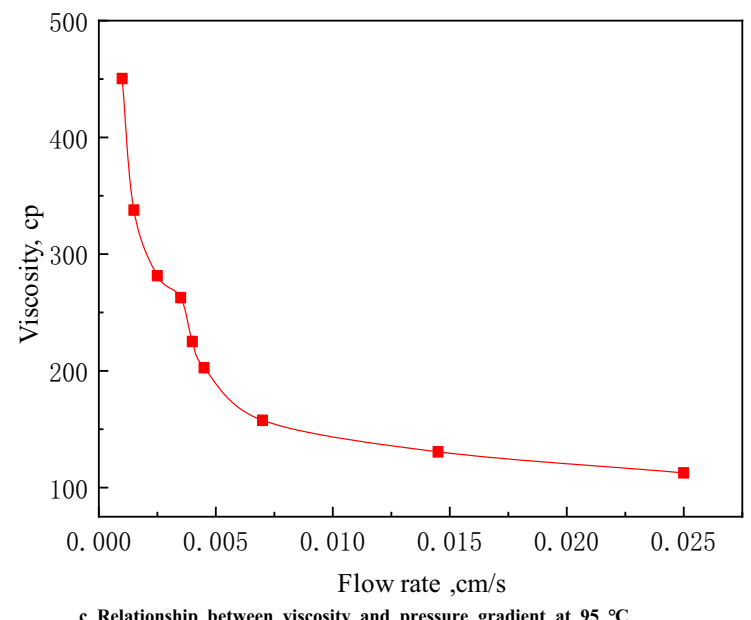

Fig. 25 Seepage characteristics at $95{ }^{\circ} \mathrm{C}$

increase in temperature. When it is higher than $85^{\circ} \mathrm{C}$, the decrease range decreases. The temperature rises from 65 to $105^{\circ} \mathrm{C}$, and the viscosity of crude oil under formation conditions decreases from 7732.22 to $1188.46 \mathrm{cp}$.

3. The viscosity-temperature test shows that the viscosity of crude oil decreases with the increase in shear rate 

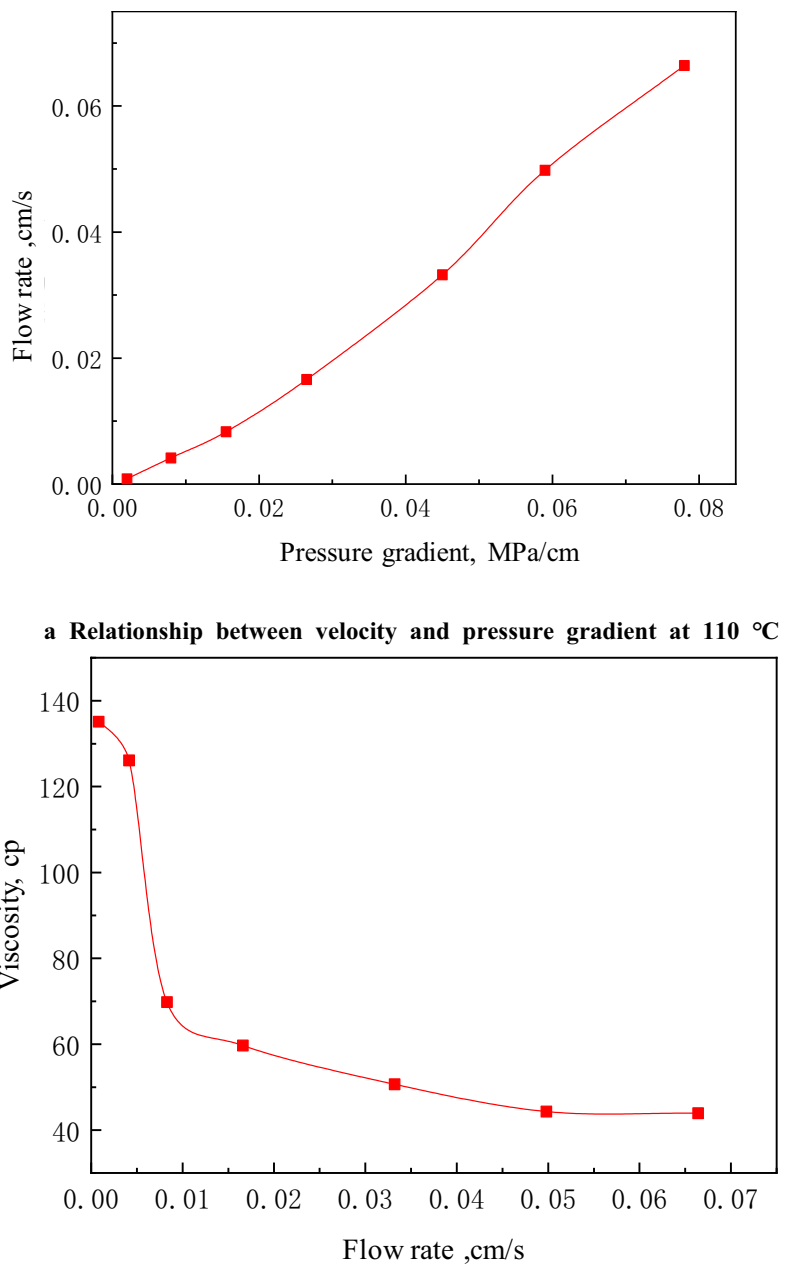

b Relationship between viscosity and pressure gradient at $110{ }^{\circ} \mathrm{C}$

Fig. 26 Seepage characteristics at $110{ }^{\circ} \mathrm{C}$

at the same temperature, showing the characteristics of shear thinning. With the increase in temperature, the crude oil viscosity first decreases rapidly. When the temperature is higher than $80{ }^{\circ} \mathrm{C}$, the decrease range of crude oil viscosity decreases.

4. The capillary viscosity experiment shows that when the GOR of crude oil is 4 , and the flow rate is $0.2 \mathrm{~mL} / \mathrm{min}$, the crude oil viscosity is $3540-991 \mathrm{cp}$. The viscosity of crude oil is between 2815 and $226 \mathrm{cp}$ at the flow rate of $0.5 \mathrm{~mL} / \mathrm{min}$. With the increase in temperature, the viscosity decreases, the shear rate increases and the viscosity decreases.

5. The percolation experiment of crude oil core shows that when the temperature is $65{ }^{\circ} \mathrm{C}$ and $95{ }^{\circ} \mathrm{C}$, and the pres-

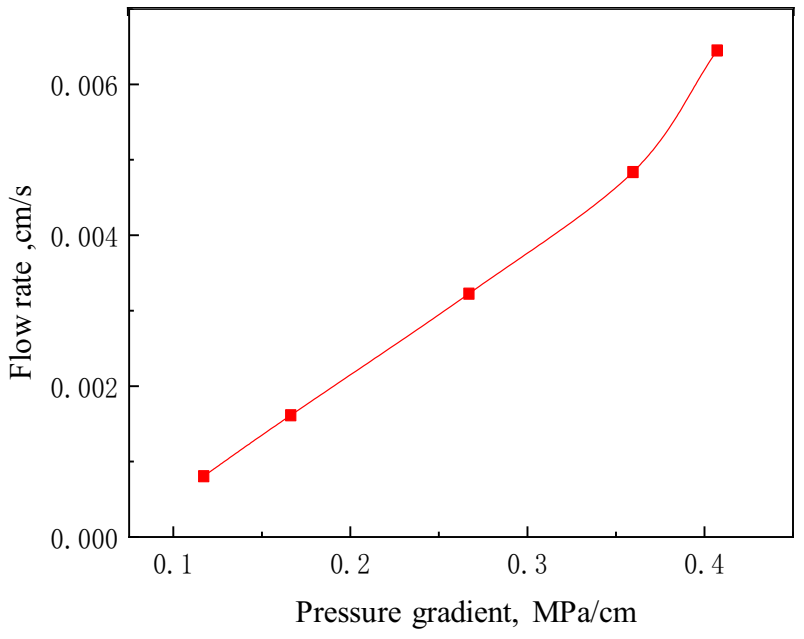

a Relationship between velocity and pressure gradient at $55{ }^{\circ} \mathrm{C}$

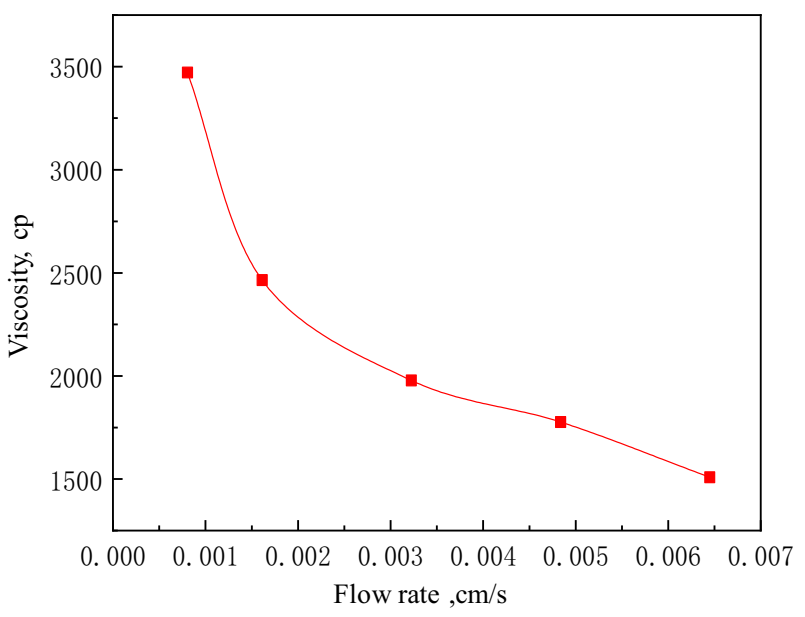

Fig. 27 Seepage characteristics at $55^{\circ} \mathrm{C}$

Table 8 Relationship between crude oil viscosity and flow rate

\begin{tabular}{lll}
\hline Temperature $\left({ }^{\circ} \mathrm{C}\right)$ & Expression & $\begin{array}{l}\text { Correlation } \\
\text { coefficient }\end{array}$ \\
\hline 65 & $\mu=107.08 \mathrm{~V}^{-0.25}$ & 0.9045 \\
95 & $\mu=24.482 \mathrm{~V}^{-0.305}$ & 0.9872 \\
110 & $\mu=19.23 \mathrm{~V}^{-0.29}$ & 0.9159 \\
\hline
\end{tabular}

sure gradient is small, the percolation velocity increases slowly with the increase in pressure gradient, and the relationship between percolation velocity and pressure gradient is a curve of concave velocity axis. With the increase in pressure gradient, the seepage velocity increases. When the pressure gradient reaches a certain value, the seepage velocity and pressure gradient gradually become linear. When the temperature is $110{ }^{\circ} \mathrm{C}$, the 


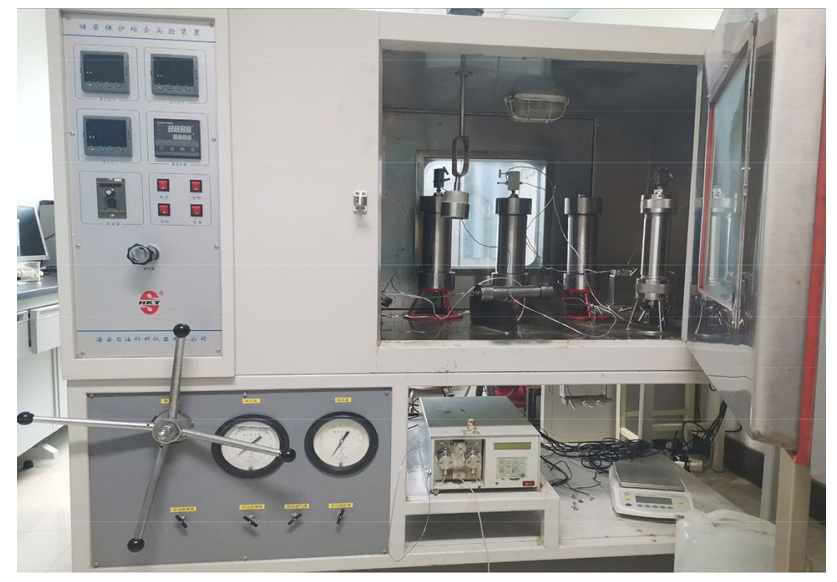

Fig. 28 High temperature and high-pressure displacement equipment

seepage velocity is approximately linear with the pressure gradient.

6. The percolation experiment of crude oil core shows that the crude oil viscosity first decreases rapidly with the increase in percolation velocity and then tends to be flat, forming a power function relationship. The crude oil viscosity ranges from 600 to $730 \mathrm{cp}$ at the formation temperature of $65^{\circ} \mathrm{C}$.

\section{Depletion mining experiment}

\section{Experimental methods}

Experimental instrument: High temperature and high-pressure displacement equipment, as shown in Fig. 28.

Experimental materials: Degassed crude oil, methane, and ethane; Quartz sand.

Experimental objective: Analyze the depletion production characteristics of heavy oil under different conditions and clarify the oil and gas production characteristics and influencing factors of depletion production.

Experiment steps

1. According to the bubble point pressure, temperature $\left(65^{\circ} \mathrm{C}\right)$ and dissolved gas-oil ratio, the live oil was compounded;

2. The volume of saturated water is the pore volume, and the porosity is the ratio of pore volume to the volume of the sand filling pipe. The temperature of the incubator is $65{ }^{\circ} \mathrm{C}$;

3. Connect the displacement device and inject water, measure the pressure difference at both ends of the sand filling pipe under different flow steady states, calculate the permeability of the sand filling pipe, and ensure that the

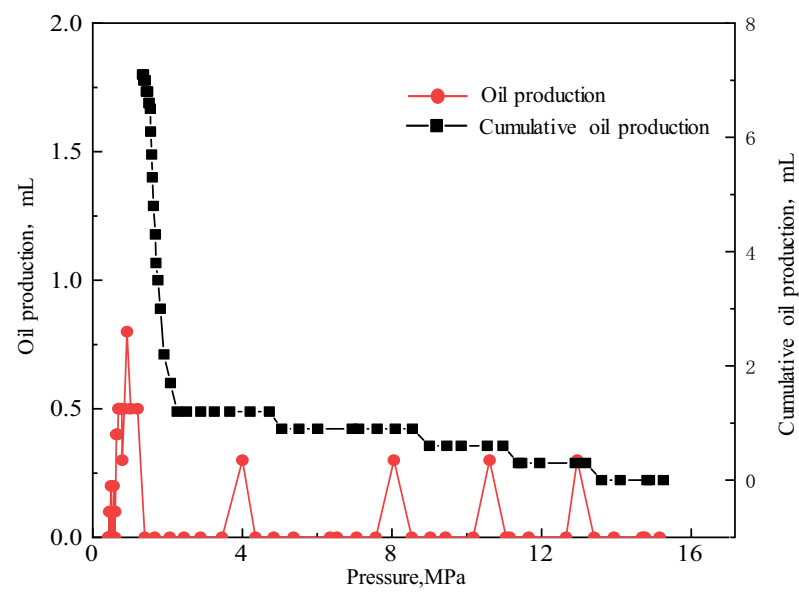

a. $5 \mathrm{MPa} / \mathrm{h}$ depletion production curve

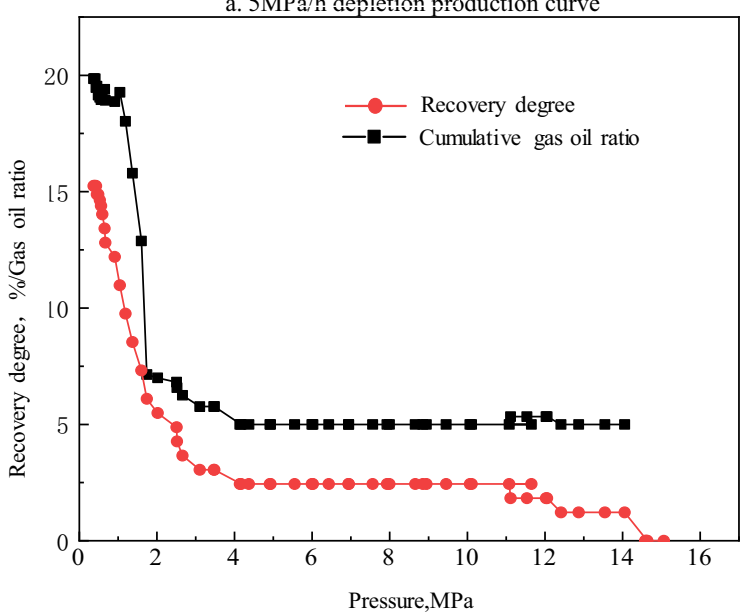

b. $5 \mathrm{MPa} / \mathrm{h}$ depletion recovery gas-oil ratio and recovery degree curve

Fig. $295 \mathrm{MPa} / \mathrm{h}$ depletion mining curve

permeability of the sand filling pipe is in the range of $1000-1800 \mathrm{mD}$;

4. The core is saturated with live oil, the backpressure is set at $15 \mathrm{MPa}$, the initial oil saturation is calculated according to the produced water, and the core is aged for $24 \mathrm{~h}$ under the formation temperature;

5. According to the set pressure drop rate $(5 \mathrm{MPa} / \mathrm{h}$, 7.5 MPa/h, $15 \mathrm{MPa} / \mathrm{h}$ ), gradually reduce the backpressure, and record the variation of oil production and gas production with pressure in the process of depletion development;

6. Analysis of oil and gas production data, evident production characteristics under different conditions, and analysis of depletion production factors.

\section{Experimental result}

The experiments under different depletion mining rates (5 MPa/h, $7.5 \mathrm{MPa} / \mathrm{h}, 15 \mathrm{MPa} / \mathrm{h}$ ) were carried out through the sand filling pipe experiment. 


\section{$5 \mathrm{MPa} / \mathrm{h}$ speed depletion mining}

The permeability of the sand filling pipe is $1315 \mathrm{mD}$, the dripping water is $45 \mathrm{~mL}$, the porosity is $45.9 \%$, the saturated oil is $40 \mathrm{~mL}$, the oil saturation is 0.89 , and the temperature of the incubator is $65^{\circ} \mathrm{C}$. When the depletion production is carried out at the speed of $5 \mathrm{MPa} / \mathrm{h}$, the experimental results are shown in Fig. 29.

It can be seen from Fig. 29 that when the pressure is higher than the bubble point, the oil output is smaller, and the cumulative oil production increases slowly. When the pressure is lower than the bubble point, the oil output increases and the cumulative oil production increases faster. When the pressure continues to decrease, the oil output gradually decreases. When the pressure is higher than the bubble point, the gas-oil ratio remains relatively stable. When the pressure is lower than the bubble point, the gas-oil ratio

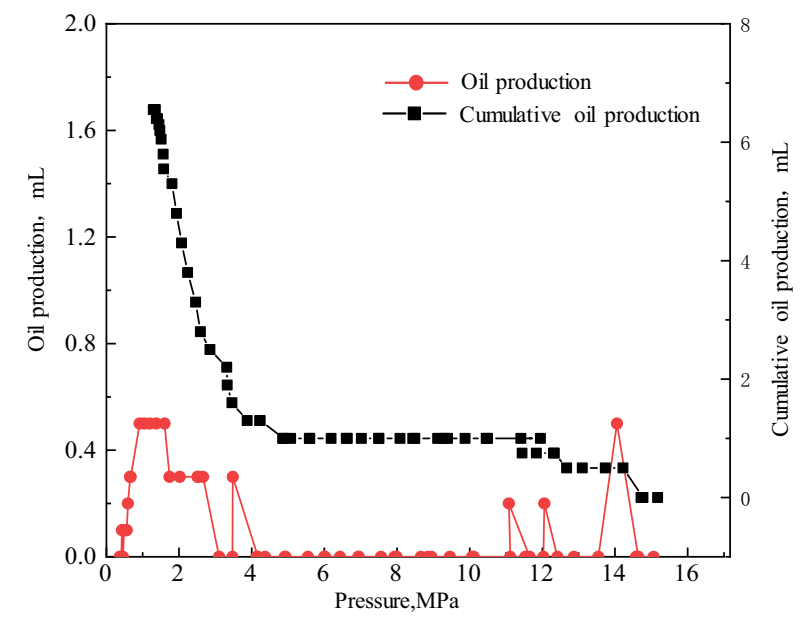

a. $7.5 \mathrm{MPa} / \mathrm{h}$ depletion production curve

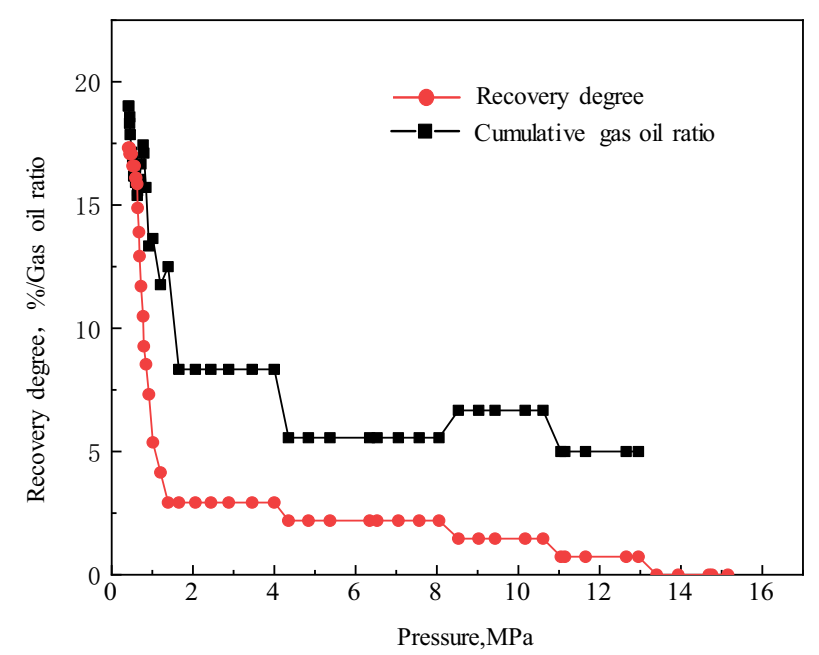

b $7.5 \mathrm{MPa} / \mathrm{h}$ depletion recovery gas-oil ratio and recovery degree curve fluctuates slightly, the pressure continues to decrease, and the gas-oil ratio increases rapidly $38 \%$.

\section{$5 \mathrm{MPa} / \mathrm{h}$ speed depletion mining}

The permeability of the sand filling pipe is $1233 \mathrm{mD}$, the dripping water is $43 \mathrm{~mL}$, the porosity is $43.8 \%$, the saturated oil is $37 \mathrm{~mL}$, the oil saturation is 0.86 , and the temperature of the incubator is $65{ }^{\circ} \mathrm{C}$. When the depletion production is carried out at the speed of $7.5 \mathrm{MPa} / \mathrm{h}$, the experimental results are shown in Fig. 30.

It can be seen from Fig. 30 that when the pressure is higher than the bubble point, the oil output is smaller, and the cumulative oil production increases slowly. When the pressure is lower than the bubble point, the oil output increases and the cumulative oil production increases faster. When the pressure continues to decrease, the oil output gradually decreases. When the pressure is higher than the bubble point, the gas-oil ratio remains relatively stable. When the

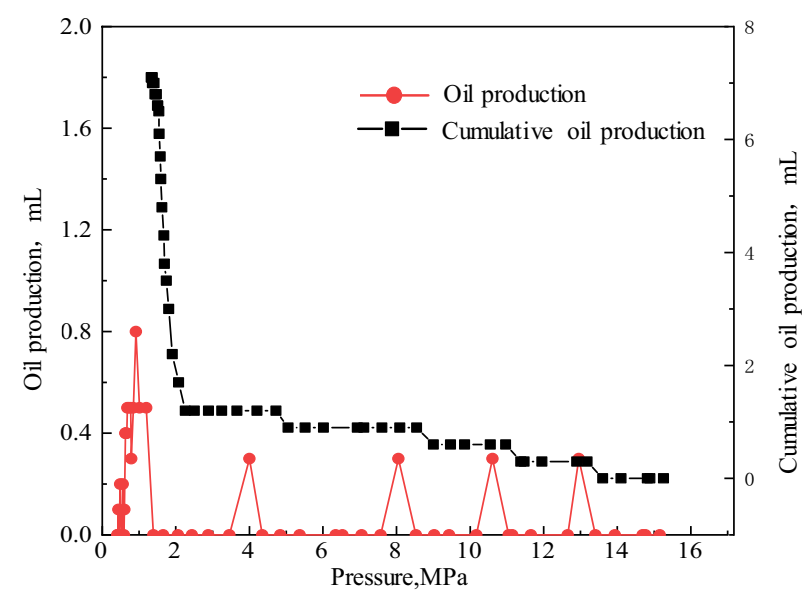

a $15 \mathrm{MPa} / \mathrm{h}$ depletion production curve

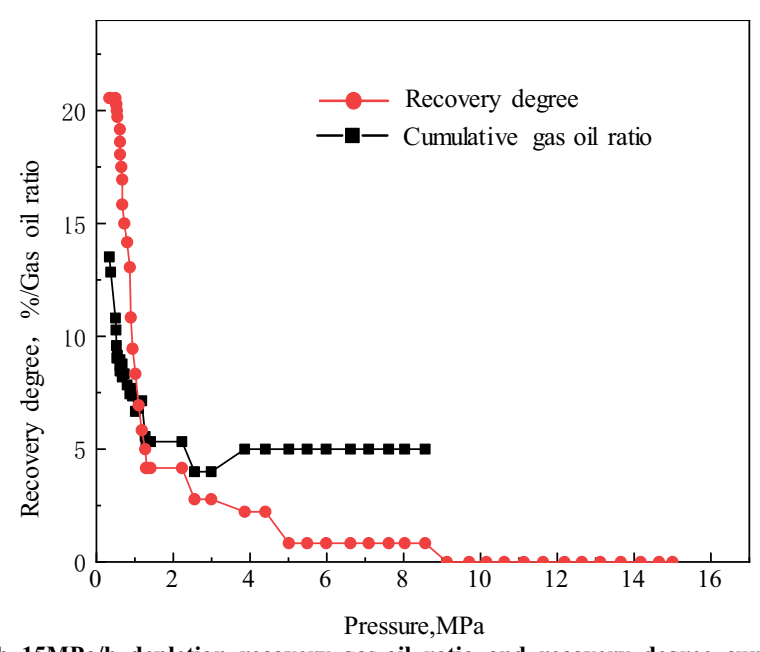

b $15 \mathrm{MPa} / \mathrm{h}$ depletion recovery gas-oil ratio and recovery degree curve

Fig. $307.5 \mathrm{MPa} / \mathrm{h}$ depletion mining curve

Fig. $3115 \mathrm{MPa} / \mathrm{h}$ depletion mining curve 
pressure is lower than the bubble point, the gas-oil ratio fluctuates slightly, the pressure continues to decrease, and the gas-oil ratio increases rapidly $32 \%$.

\section{$15 \mathrm{MPa} / \mathrm{h}$ speed depletion mining}

The permeability of the sand filling pipe is $1287 \mathrm{mD}$, the dripping water is $40 \mathrm{~mL}$, the porosity is $40.8 \%$, the saturated oil is $36 \mathrm{~mL}$, the oil saturation is 0.90 , and the temperature of the incubator is $65{ }^{\circ} \mathrm{C}$. When the depletion production is carried out at the speed of $15 \mathrm{MPa} / \mathrm{h}$, the experimental results are shown in Fig. 31.

It can be seen from Fig. 31 that when the pressure is higher than the bubble point, the oil output is smaller, and the cumulative oil production increases slowly. When the pressure is lower than the bubble point, the oil output increases and the cumulative oil production increases faster. When the pressure continues to decrease, the oil output gradually decreases. When the pressure is higher than the bubble point, the gas-oil ratio remains relatively stable. When the pressure is lower than the bubble point, the gas-oil ratio fluctuates slightly, the pressure continues to decrease, and the gas-oil ratio increases rapidly $80 \%$.

\section{Summary}

It can be seen from the above experiments that when the pressure is higher than the bubble point, less oil is produced; when the pressure is lower than the bubble point, more oil is produced, and most of the crude oil is produced below the bubble point pressure. When the pressure is higher than the bubble point pressure, the crude oil is single-phase, and the compressibility is slight. The crude oil is produced by decompression and expansion. When the pressure is lower than the bubble point pressure, the dissolved gas drive is formed. At the same time, some dissolved gas would form bubbles in the crude oil, which increases the elastic energy of the crude oil. At the same time, the faster the pressure drop, the higher the degree of oil recovery (Table 9). The faster the pressure drop, the lower the viscosity of the crude oil, and the more pronounced the phenomenon of foam oil.

Table 9 Recovery factor under different depletion mining rates

\section{Experiment on oil displacement efficiency of water flooding}

\section{Experimental methods}

Experimental instrument: High temperature and high-pressure displacement equipment, as shown in Fig. 28.

Experimental materials: Degassed crude oil, methane, and ethane; Quartz sand.

Experimental objective: The experiment aims to analyze the water drive recovery characteristics of heavy oil under different conditions and identify the influencing factors of water drive.

The experimental steps were as follows

1. According to the bubble point pressure, temperature $\left(65^{\circ} \mathrm{C}\right)$ and dissolved gas-oil ratio, the live oil was compounded;

2. The volume of saturated water is the volume of water injection, the porosity is the ratio of the volume of water injection and the volume of sand filling pipe, and the temperature of the incubator is the reservoir temperature;

3. Connect the experimental device and inject water, test the pressure difference at both ends of the sand filling pipe, calculate the permeability of the sand filling pipe, and control the permeability of the sand filling pipe at about $1500 \mathrm{mD}$, as shown in Fig. 28;

4. The core is saturated with live oil, the backpressure is set at $15 \mathrm{MPa}$, the initial oil saturation is calculated according to the produced water, and the core is aged for $24 \mathrm{~h}$ under the formation temperature;

5. According to the set pressure drop rate of $5 \mathrm{MPa} / \mathrm{h}$, gradually reduce the backpressure to the displacement pressure, and record the relationship between oil production and gas production and pressure in the process of depletion development;

6. After the pressure is reduced, the subsequent water flooding is carried out at $0.5 \mathrm{~mL} / \mathrm{min}, 1 \mathrm{~mL} / \mathrm{min}$, and $1.5 \mathrm{~mL} /$ $\mathrm{min}$, and the changes of pressure, oil production, and water production are recorded. Water flooding experiment was carried out by setting different displacement pressure;

7. Change the parameters, repeat (1)-(5), and carry out water flooding experiments with other factors.

\section{Experimental result}

\begin{tabular}{ll}
\hline $\begin{array}{l}\text { Depleted mining } \\
\text { rates }(\mathrm{MPa} / \mathrm{h})\end{array}$ & $\begin{array}{l}\text { Recovery } \\
\text { ratio }(\%)\end{array}$ \\
\hline 5 & 16.38 \\
7.5 & 17.32 \\
15 & 20.8 \\
\hline
\end{tabular}

\section{The pressure drops to atmospheric pressure}

The permeability of the sand filling pipe is $1315 \mathrm{mD}$, the dripping water is $45 \mathrm{~mL}$, the porosity is $45.9 \%$, the saturated 


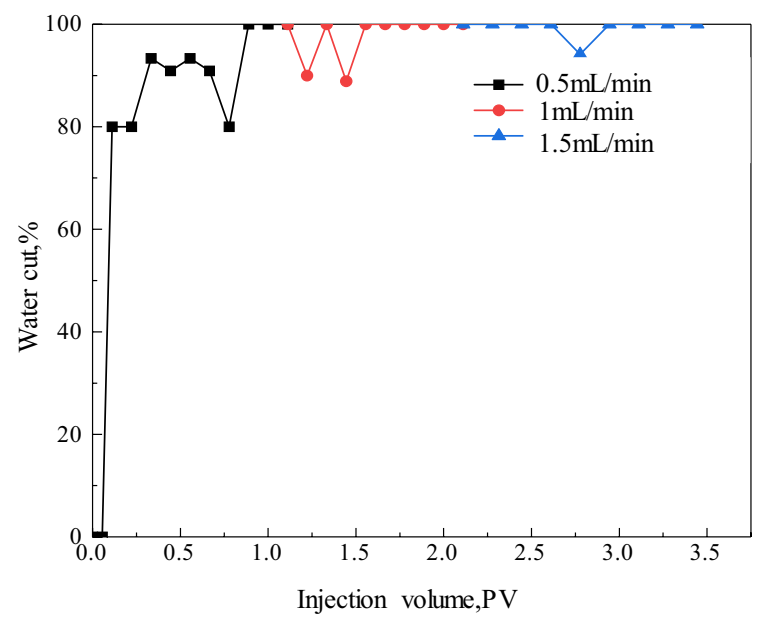

a. Water content curve of pressure drop to atmospheric pressure

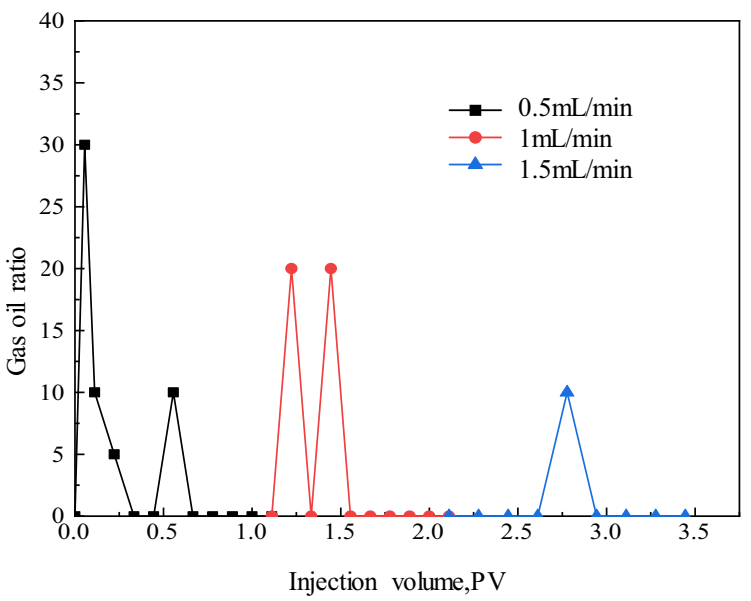

b. Gas oil ratio curve of pressure drop to atmospheric pressure

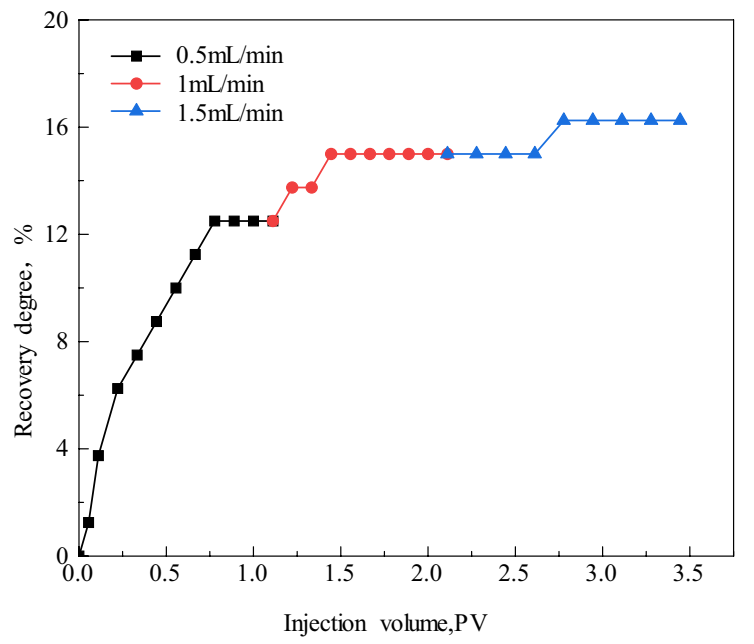

c. Recovery degree curve of pressure drop to atmospheric pressu re

Fig. 32 The dynamic curve of pressure drop to atmospheric pressure

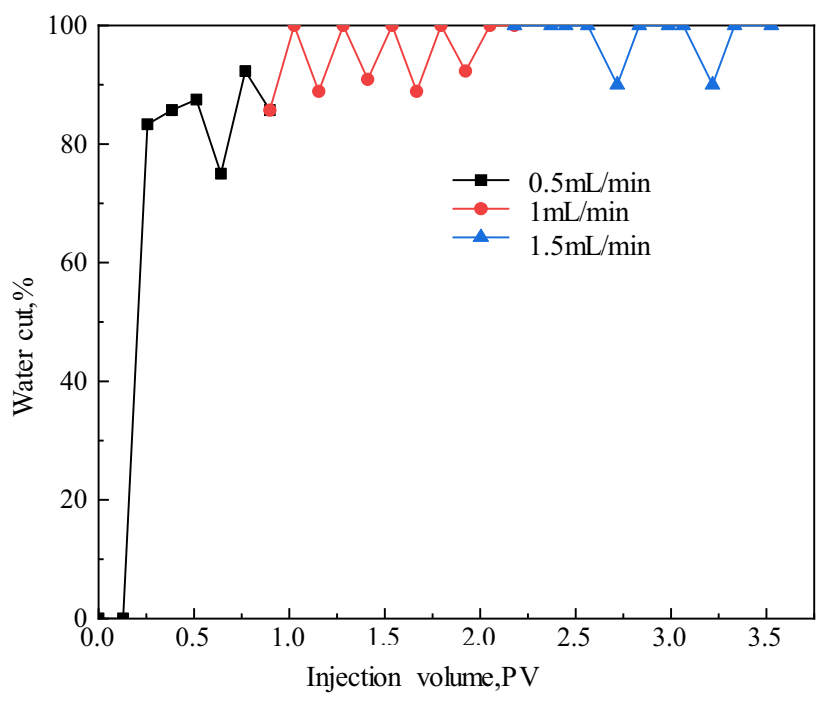

a Water content curve of pressure drop to $3 \mathrm{MPa}$

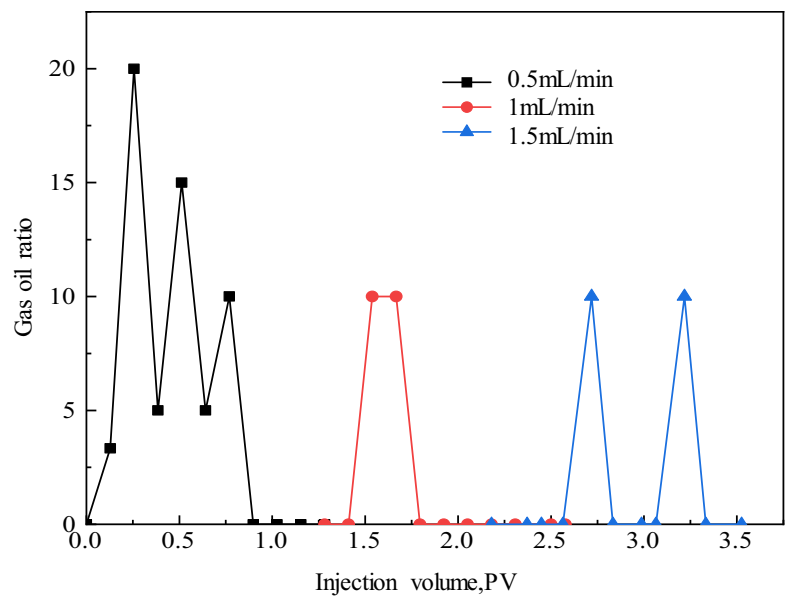

b Gas oil ratio curve of pressure drop to $3 \mathrm{MPa}$

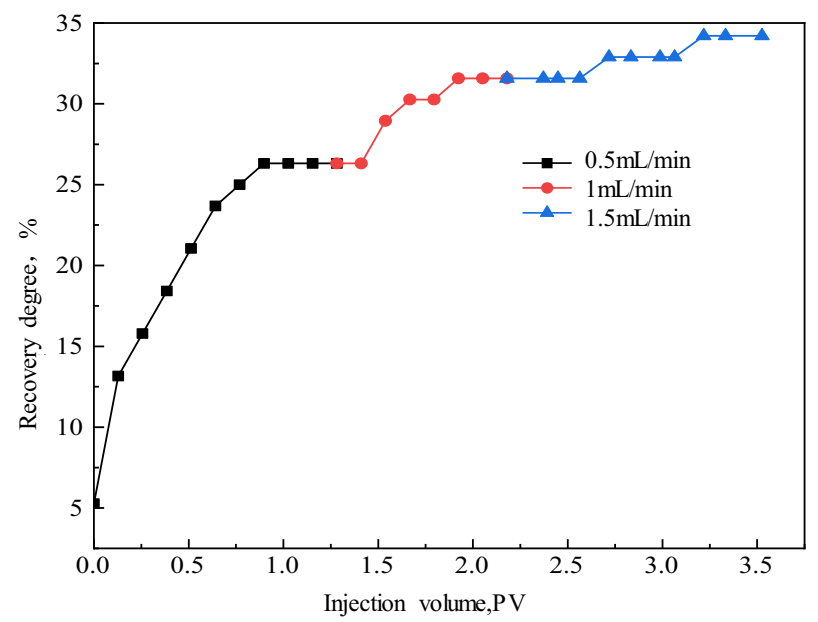

c Recovery degree curve of pressure drop to 3MPa

Fig. 33 Dynamic curve of pressure drop to $3 \mathrm{MPa}$ 
oil is $40 \mathrm{~mL}$, the oil saturation is 0.89 , and the incubator temperature is $65{ }^{\circ} \mathrm{C}$. The experimental results are shown in Fig. 32.

It can be seen from Fig. 32 that during water injection displacement, due to the unfavorable oil-water mobility ratio, the water breakthrough is earlier, and $0.11 \mathrm{PV}$ water breakthrough is injected. After water breakthrough, the water cut rises rapidly and rapidly rises to more than $80 \%$. Most of the crude oil is produced at high water cut; $0.5 \mathrm{~mL} / \mathrm{min}$ to $1 \mathrm{~mL} /$ $\min$ and $0.61 \%$ to $1.5 \mathrm{~mL} / \mathrm{min}$. Therefore, the total recovery of the water drive is increased by $15.61 \%$. At the same time, when the injection rate is higher, the viscosity of crude oil would decrease so that the recovery degree would increase. Thus, the total recovery of depletion and water flooding is $32.75 \%$.

\section{The pressure drops to $3 \mathrm{MPa}$}

The permeability of sand filling pipe is $1425 \mathrm{mD}$, the porosity is $39.75 \%$, the dripping water is $39 \mathrm{~mL}$, the saturated oil is $38 \mathrm{~mL}$, and the incubator temperature is $65^{\circ} \mathrm{C}$. The experimental results are shown in Fig. 33.

It can be seen from Fig. 33 that during water injection displacement, 0.26 PV water breakthrough is injected, and after water breakthrough, the water cut rises rapidly to more than $80 \%$. Most of the crude oil is produced at high water cut. When the injection rate is $0.5 \mathrm{~mL} / \mathrm{min}$, the recovery degree is increased by $21.06 \%$. When the injection rate is increased to $1 \mathrm{~mL} / \mathrm{min}$, the recovery degree increases by $5.26 \%$. When the injection rate increases to $1.5 \mathrm{~mL} / \mathrm{min}$, the recovery degree increases by $2.63 \%$. The total recovery degree of water drive is increased by $28.95 \%$. At the same time, when the injection rate is higher, the viscosity of crude oil would decrease so that the recovery degree would increase. The total recovery rate of depletion and water flooding is $34.21 \%$.

\section{The pressure drops to $8 \mathrm{MPa}$}

The permeability of sand filling pipe is $1326 \mathrm{mD}$, the porosity is $38.73 \%$, the dripping water is $38 \mathrm{~mL}$, the saturated oil is $35 \mathrm{~mL}$, and the incubator temperature is $65^{\circ} \mathrm{C}$. The experimental results are shown in Fig. 34.

It can be seen from Fig. 34 that when the pressure is reduced to $8 \mathrm{MPa}, 0.26 \mathrm{PV}$ water breakthrough is injected. After the water breakthrough, the water cut rises rapidly and rises to more than $80 \%$. After the water breakthrough, oil continues to be produced at high water cut, and most crude oil is produced at high water cut. $0.5 \mathrm{~mL} / \mathrm{min}$, the recovery rate is $27.14 \%$, continue $1 \mathrm{~mL} / \mathrm{min}$ water flooding, improve the recovery rate by $2.86 \%, 1.5 \mathrm{~mL} /$ min improve the recovery rate by $1.43 \%$. Appropriately

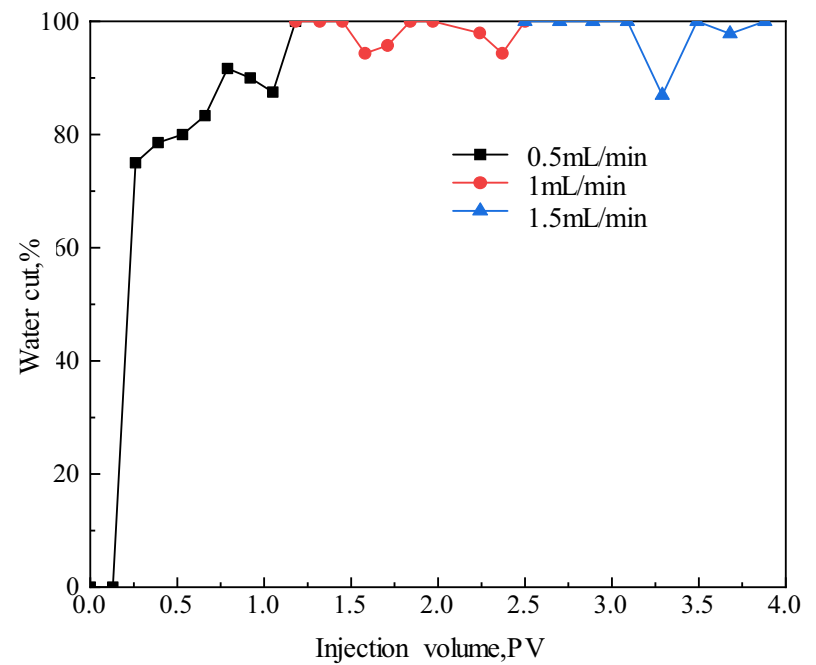

a. Water content curve of pressure drop to $8 \mathrm{MPa}$

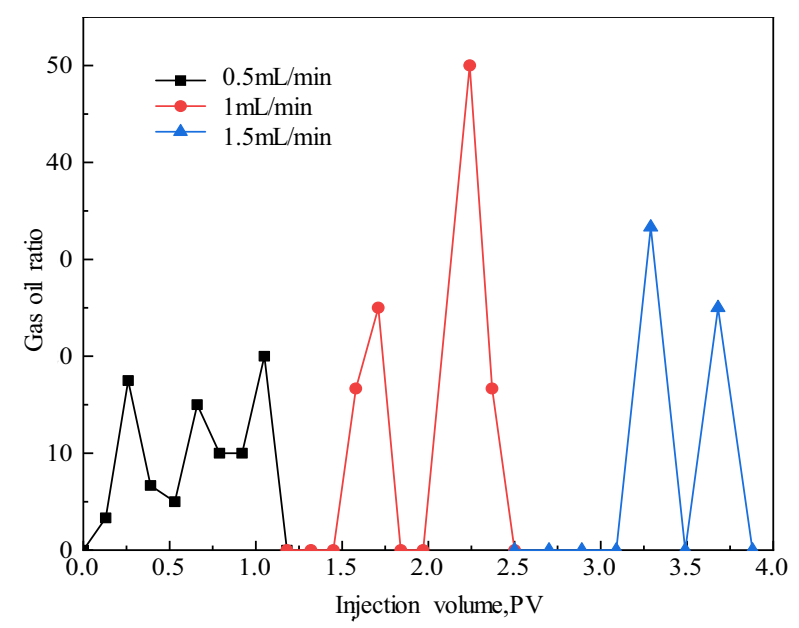

b. Gas oil ratio curve of pressure drop to $8 \mathrm{MPa}$

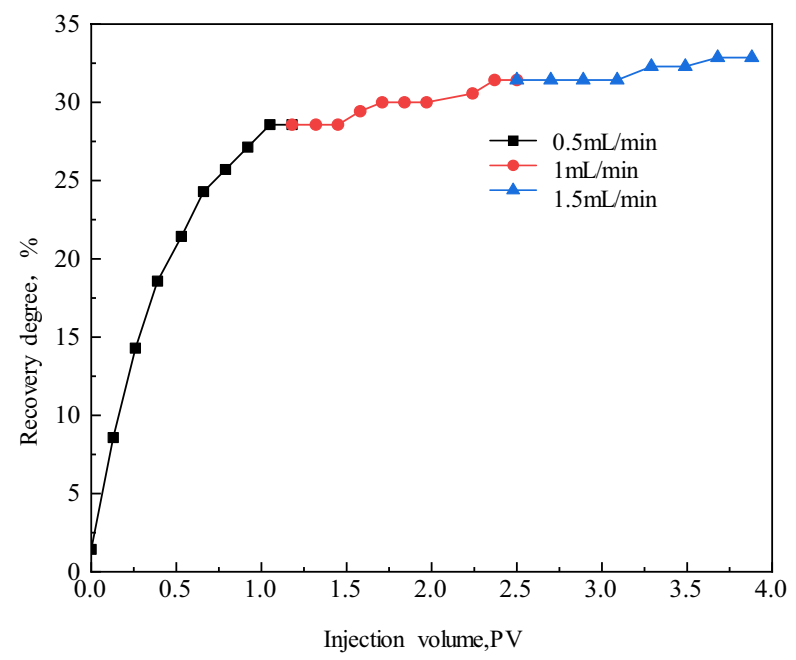

c. Recovery degree curve of pressure drop to $8 \mathrm{MPa}$

Fig. 34 The dynamic curve of pressure drop to $8 \mathrm{MPa}$ 


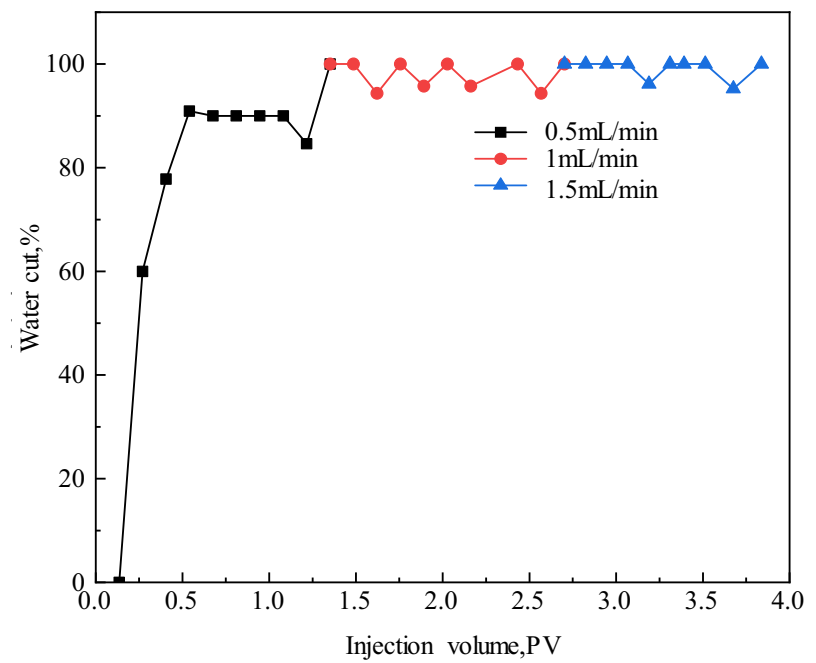

a. Water content curve at $100^{\circ} \mathrm{C}$

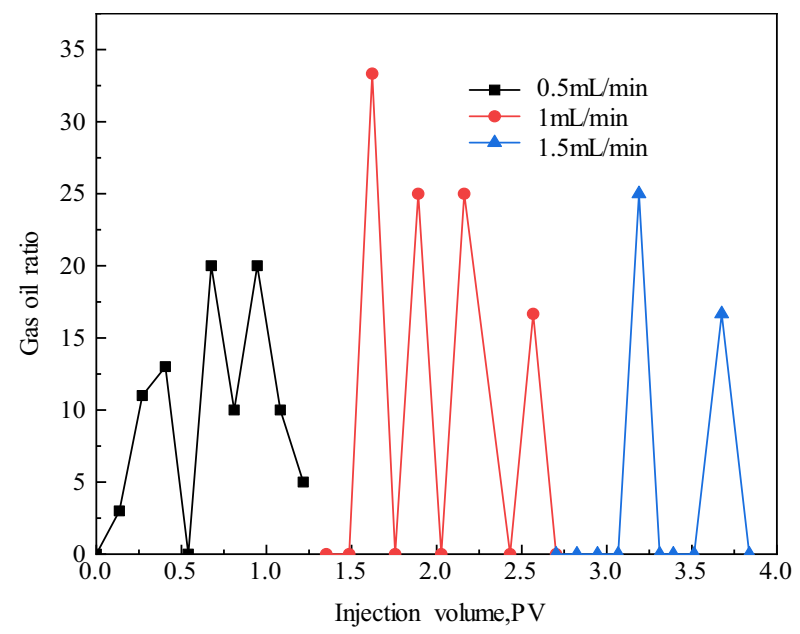

b. Gas oil ratio curve at $100{ }^{\circ} \mathrm{C}$

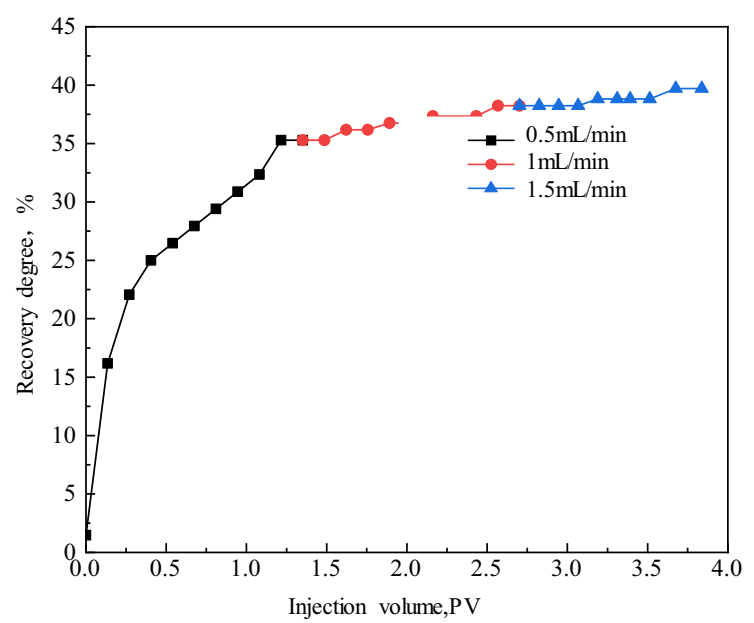

c. Recovery degree curve at $100{ }^{\circ} \mathrm{C}$ increasing the water injection rate can increase the swept volume and the recovery degree. The total recovery rate of water flooding is increased by $31.43 \%$. At the same time, when the injection rate is higher, the viscosity of crude oil would decrease so that the recovery degree would increase. The total recovery rate of depletion and water flooding is $32.86 \%$.

\section{${ }^{\circ} \mathrm{C}$ water flooding}

By changing the incubator's temperature, the influence of the experimental temperature on the recovery factor is studied. The permeability of the sand filling pipe is $1215 \mathrm{mD}$, the porosity is $37.71 \%$, the dripping water is $37 \mathrm{~mL}$, the saturated oil is $34 \mathrm{~mL}$, the incubator's temperature is $100^{\circ} \mathrm{C}$, and the pressure is reduced to $8 \mathrm{MPa}$. The experimental results are shown in Fig. 35.

It can be seen from Fig. 35 that when the temperature rises to $100{ }^{\circ} \mathrm{C}$ and the pressure drop to $8 \mathrm{Mpa}$, the water breakthrough is $0.27 \mathrm{PV}$. After the water breakthrough, the water cut rises rapidly to more than $80 \%$. Most of the crude oil is produced at high water cuts. The recovery rate is $33.82 \%$ when the water injection rate is $0.5 \mathrm{~mL} / \mathrm{min}, 2.95 \%$ when the water injection rate is $1 \mathrm{~mL} / \mathrm{min}$, and $1.47 \%$ when the water injection rate is $1.5 \mathrm{~mL} / \mathrm{min}$. Properly increasing water injection rate and formation temperature can increase swept volume and recovery degree. The total recovery degree of depletion and water flooding is $39.71 \%, 6.85 \%$ higher than $65{ }^{\circ} \mathrm{C}$. As the temperature increases, the viscosity of crude oil decreases, the oil-water mobility ratio decreases, and the water flooding effect is improved.

\section{Summary}

It can be seen from the above experiments that the water drive effect is related to the water drive speed. The higher the water drive speed is, the higher the oil drive efficiency is. At the same time, it is related to the timing of water injection. When water is injected near the bubble point pressure, the total recovery degree is the highest. Increasing the temperature can reduce the viscosity of crude oil, improve the oil-water mobility ratio, and increase the oil displacement efficiency by $6.85 \%$ (Table 10 ).

\section{Experiment on sweep efficiency of water flooding}

\section{Experimental methods}

Experimental materials: Degassed crude oil and kerosene. 
Table 10 Water drive oil displacement efficiency

\begin{tabular}{lllll}
\hline Development mode & \multicolumn{2}{l}{ Recovery ratio (\%) } & & \\
\cline { 2 - 5 } & Incubator's temperature is $65^{\circ} \mathrm{C}$ & $\begin{array}{l}\text { Incubator's } \\
\text { tem- } \\
\text { perature is } \\
100{ }^{\circ} \mathrm{C}\end{array}$ \\
& & & & $\begin{array}{l}\text { The pres- } \\
\text { sure drops } \\
\text { to 8 MPa }\end{array}$ \\
\cline { 2 - 5 } & The pressure drops to & The pressure & The pressure \\
atmospheric pressure & drops to 3 MPa & & 1.47 \\
depletion development & 17.14 & & 1.43 & 35.29 \\
Injection speed $0.5 \mathrm{~mL} / \mathrm{min}$ & 29.64 & 5.26 & 28.57 & 38.24 \\
Injection speed $1 \mathrm{~mL} / \mathrm{min}$ & 32.14 & 26.32 & 31.43 & 39.71 \\
Injection speed $1.5 \mathrm{~mL} / \mathrm{min}$ & 32.75 & 31.58 & 32.86 & \\
\hline
\end{tabular}

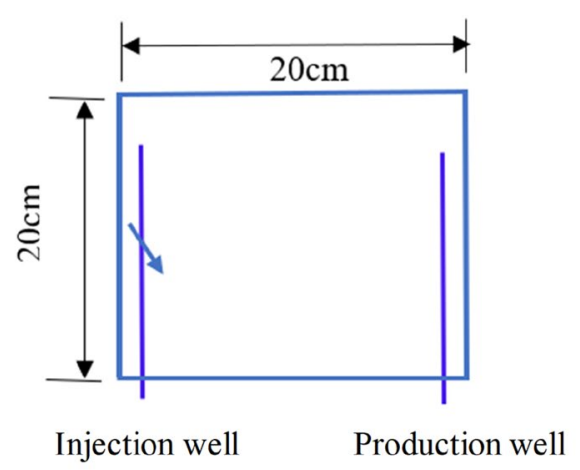

a. Visual model diagram

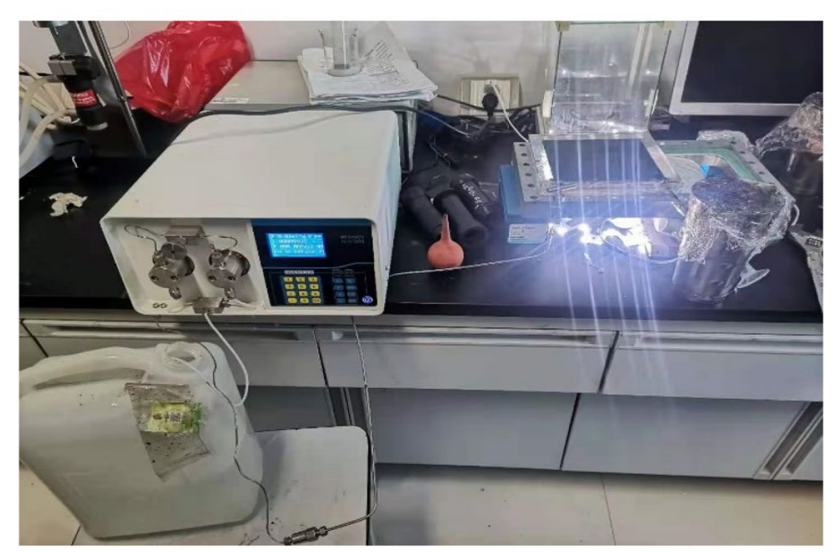

b. 2D visual simulation experiment device

Fig. 36 Visualization model

Experimental purpose: Through a 2D visual model simulation experiment, the water drive development law, oil and water production characteristics of horizontal wells with different crude oil viscosity and injection speed are studied,

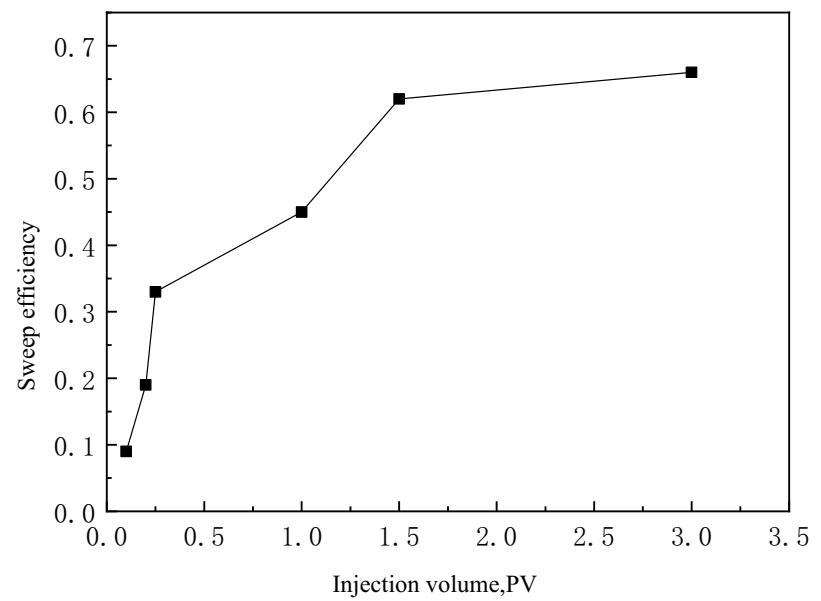

Fig. 37 Sweep efficiency curve at $500 \mathrm{cp}$

and the influencing factors of water drive sweep efficiency are analyzed.

Experiment steps

1. Make a 2D visual simulation model, and the schematic diagram of the model is shown in Fig. 36. The model's size is $20 \mathrm{~cm}$ in length, $20 \mathrm{~cm}$ in width, and $0.5 \mathrm{~cm}$ in thickness. The visualization model is filled with transparent glass beads;

2. The crude oil was mixed with kerosene, and the simulated oil with the required viscosity was prepared. The simulated oil with a specific viscosity was injected into the model, and the volume of crude oil injected into the model was recorded;

3. The model is placed for $24 \mathrm{~h}$. After the model is solidified, a specific injection rate is set for water flooding, and the sweep efficiency is measured at different times. 
Fig. 38 Different time spread under $500 \mathrm{cp}$

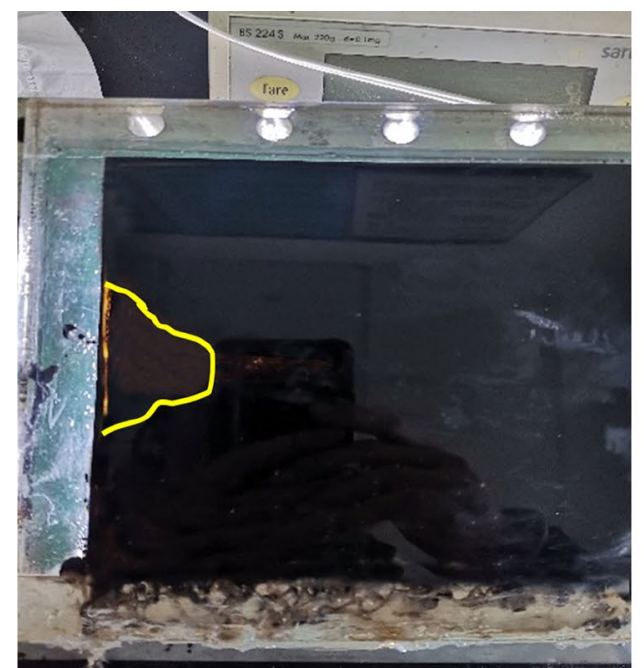

a. Injected 0.1PV

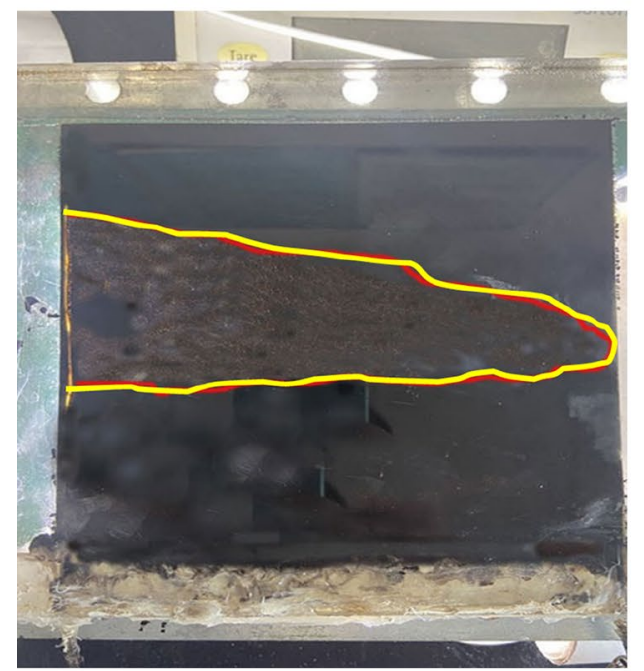

c. Water moment

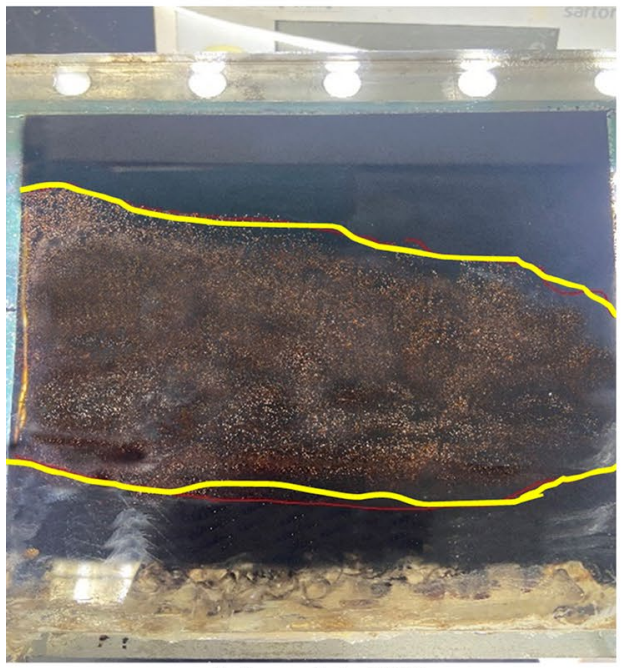

e. Injected 1.5PV

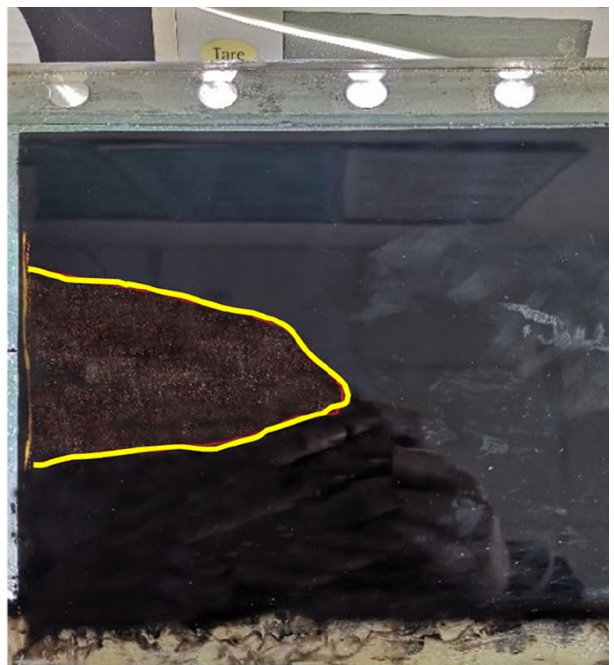

b. Injected $0.2 \mathrm{PV}$

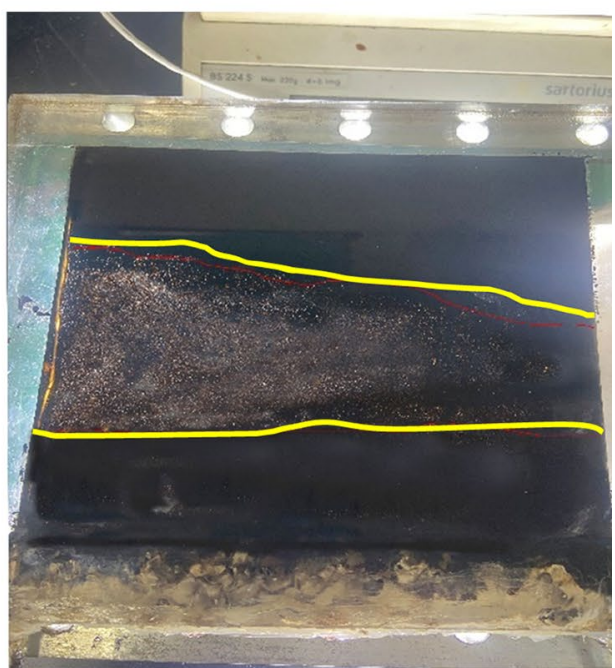

d. Injected $0.8 \mathrm{PV}$

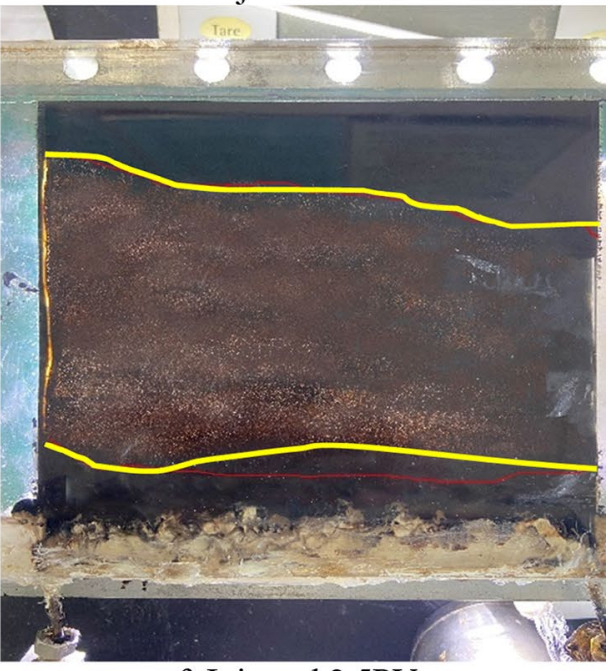

f. Injected 2.5PV 


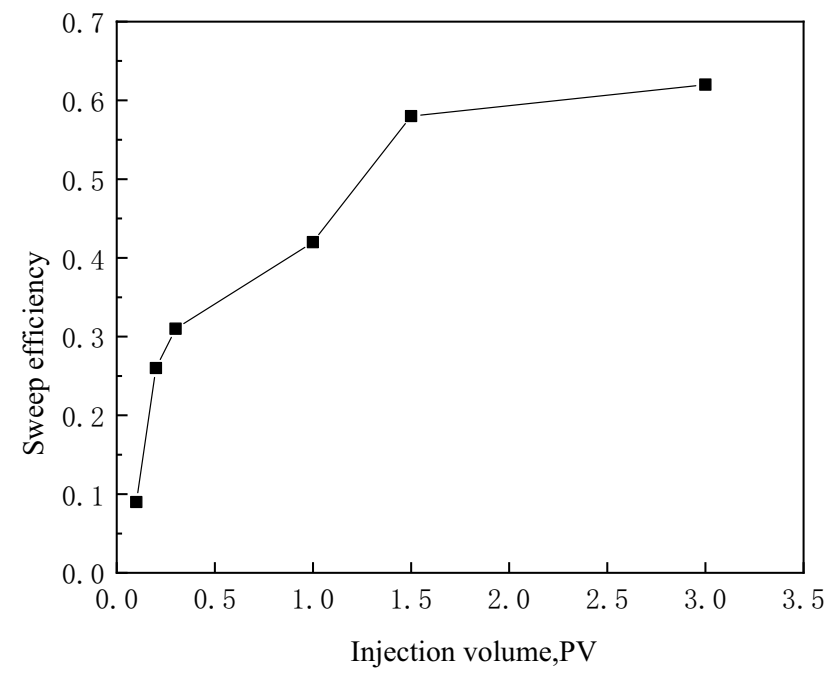

Fig. 39 Sweep efficiency curve at $700 \mathrm{cp}$

\section{Experimental result}

The simulated oil with a viscosity of 500 and $700 \mathrm{cp}$ was prepared for the water flooding experiment, and the water flooding rate was set at $1 \mathrm{~mL} / \mathrm{min}$. At the same time, to analyze the influence of injection speed on sweep efficiency, two groups of experiments with an injection speed of $0.5 \mathrm{~mL} /$ min and $1 \mathrm{~mL} / \mathrm{min}$ were carried out for crude oil with a viscosity of $500 \mathrm{cp}$.

The experimental results of viscosity $500 \mathrm{cp}$ and injection rate $1 \mathrm{~mL} / \mathrm{min}$ are shown in Fig. 37 and Fig. 38 .

It can be seen from the figure that at the beginning of water injection, the advance of the water drive front is relatively uniform. With the progress of the water drive, the injected water has a sudden advance due to fingering. When $0.25 \mathrm{pv}$ is injected, the water breakthrough occurs in the production well, and the sweep efficiency is 0.33 when water breakthrough occurs. As the water injection continues, the swept volume expands, and the final sweep efficiency is 0.66 .

The experimental results of viscosity $700 \mathrm{cp}$ and injection rate $1 \mathrm{~mL} / \mathrm{min}$ are shown in Figs. 39 and 40 .

It can be seen from the figure that the advance of the water drive front is more uniform at the beginning of water injection. With the progress of the water drive, due to the increase in crude oil viscosity, the oil-water mobility ratio becomes more extensive, the fingering is more serious, and the water breakthrough time becomes short. When $0.20 \mathrm{pv}$ is injected into the production well, the sweep coefficient is 0.26 at the water breakthrough time. As the water injection continues, the swept volume expands, and the final sweep coefficient is 0.62 .

The experimental results of viscosity of $500 \mathrm{cp}$ and injection rate of $0.5 \mathrm{~mL} / \mathrm{min}$ are shown in Figs. 41 and 42 . It can be seen that the advance of the water drive front edge is more uniform at the beginning of water injection. With the progress of the water drive, the injected water would suddenly advance due to fingering. When $0.22 \mathrm{pv}$ is injected, the water breakthrough occurs in the production well, and the sweep efficiency is 0.24 at the time of water breakthrough. As the water injection continues, the swept volume expands, and the final sweep efficiency is 0.61 .

\section{Summary}

Through the above experiments, it can be seen that the injected water would break through quickly during water injection development, and after water breakthrough, the sweep efficiency will further increase, and the sweep efficiency would decrease with the increase in crude oil viscosity but increase with the increase in injection speed (Table 11).

\section{Conclusions}

In this manuscript, through the experiment of percolation mechanism and displacement characteristics of heavy oil cold recovery, the following conclusions are obtained.

1. The crude oil PVT experiment shows that the bubble point pressure is related to the pressure drop speed. The faster the pressure drop, the lower the bubble point pressure, showing the characteristics of the foaming oil, and the foam oil phenomenon is observed in the PVT tube. The bubble point pressure of crude oil under formation conditions is $3.54 \mathrm{MPa}$.

2. The falling ball viscometer experiment shows that the higher the GOR of crude oil, the lower the crude oil viscosity. When the GOR is greater than 9, the viscosity decreases slowly. The viscosity of crude oil is sensitive to temperature and decreases rapidly with the increase in temperature. When it is higher than $85{ }^{\circ} \mathrm{C}$, the decrease range decreases. The temperature 
Fig. 40 Different time spread under $700 \mathrm{cp}$

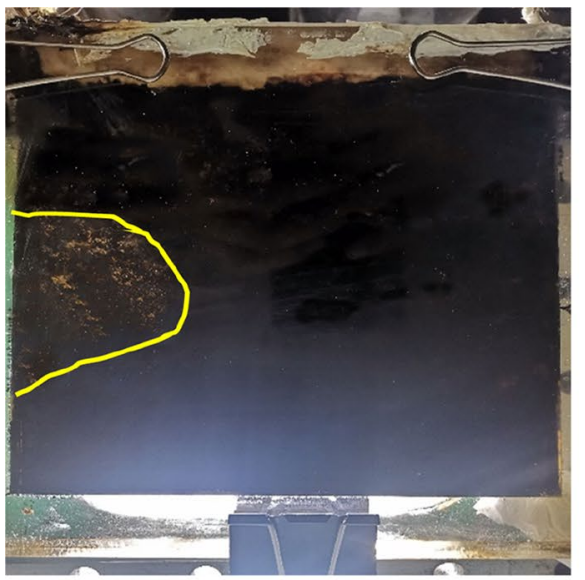

a. Injected 0.1PV

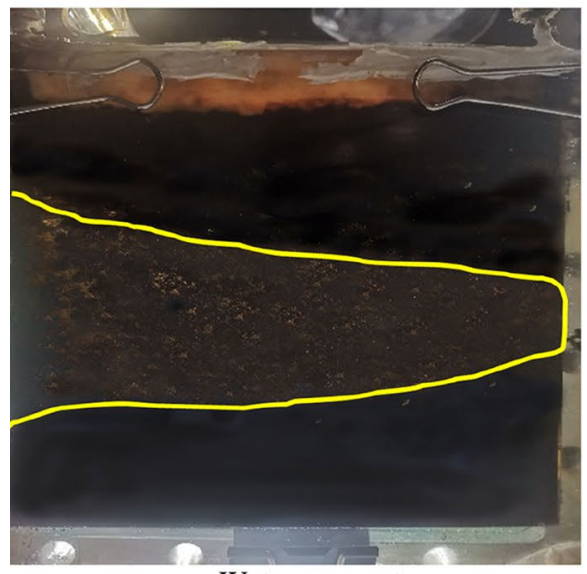

c. Water moment

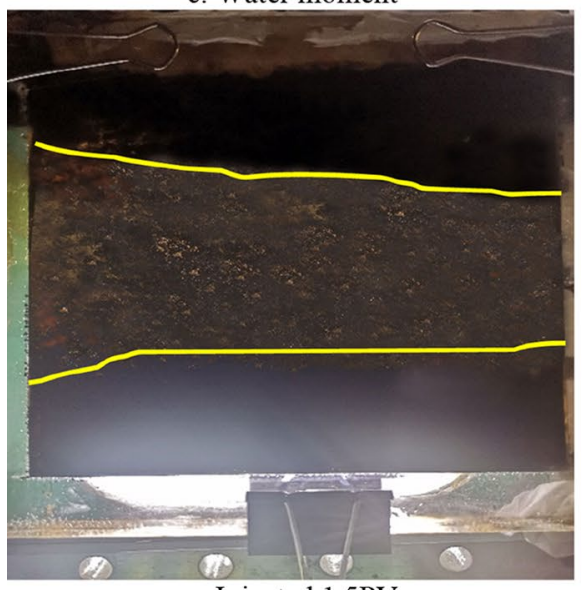

e. Injected 1.5PV

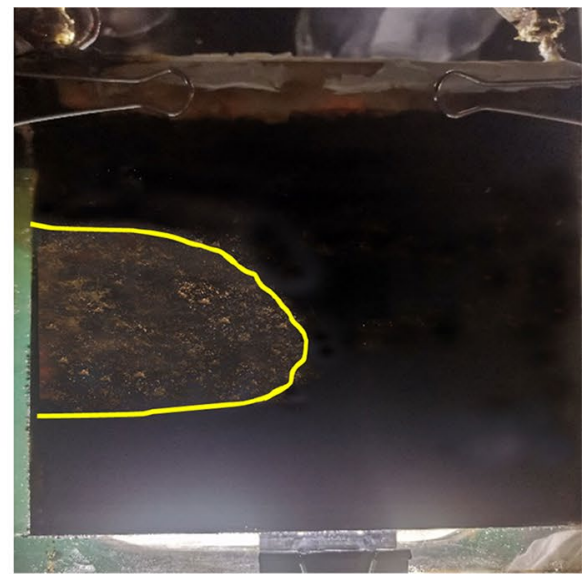

b. Injected $0.2 \mathrm{PV}$

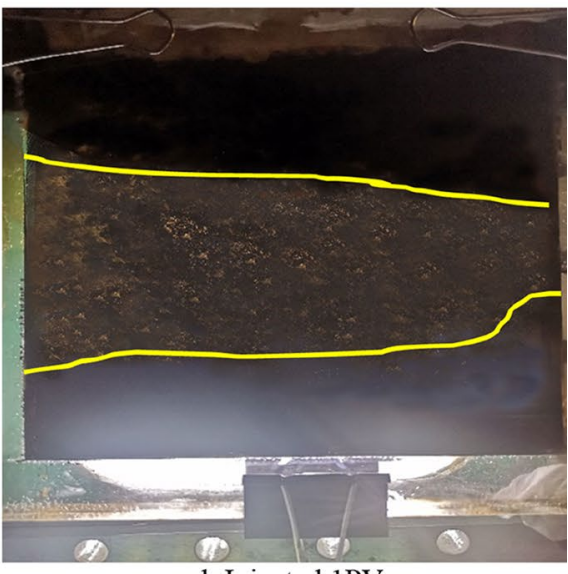

d. Injected 1PV

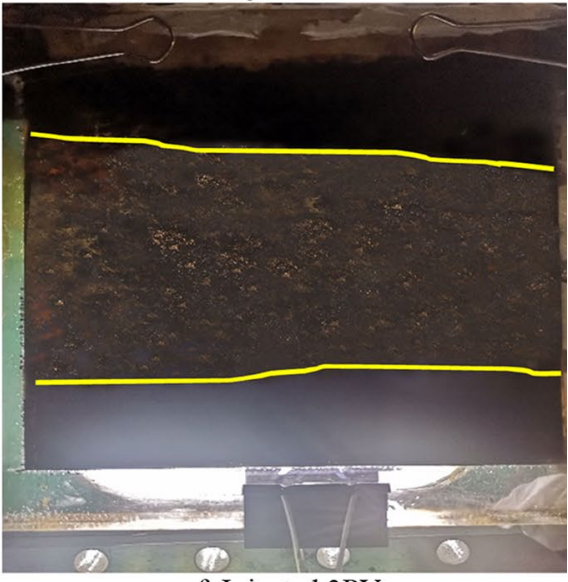

f. Injected 3PV rises from 65 to $105{ }^{\circ} \mathrm{C}$, and the viscosity of crude oil under formation conditions decreases from 7732.22 to $1188.46 \mathrm{cp}$.

3. The viscosity-temperature test shows that the viscosity of crude oil decreases with the increase in shear rate at the same temperature, showing the characteristics of shear thinning. With the increase in temperature, the crude oil viscosity first decreases rapidly. When the temperature is higher than $80{ }^{\circ} \mathrm{C}$, the decrease range of crude oil viscosity decreases.

4. The capillary viscosity experiment shows that when the GOR of crude oil is 4 , and the flow rate is $0.2 \mathrm{~mL} / \mathrm{min}$, the crude oil viscosity is $3540-991 \mathrm{cp}$. The viscosity of crude oil is between 2815 and $226 \mathrm{cp}$ at the flow rate of $0.5 \mathrm{~mL} / \mathrm{min}$. With the increase in temperature, the 


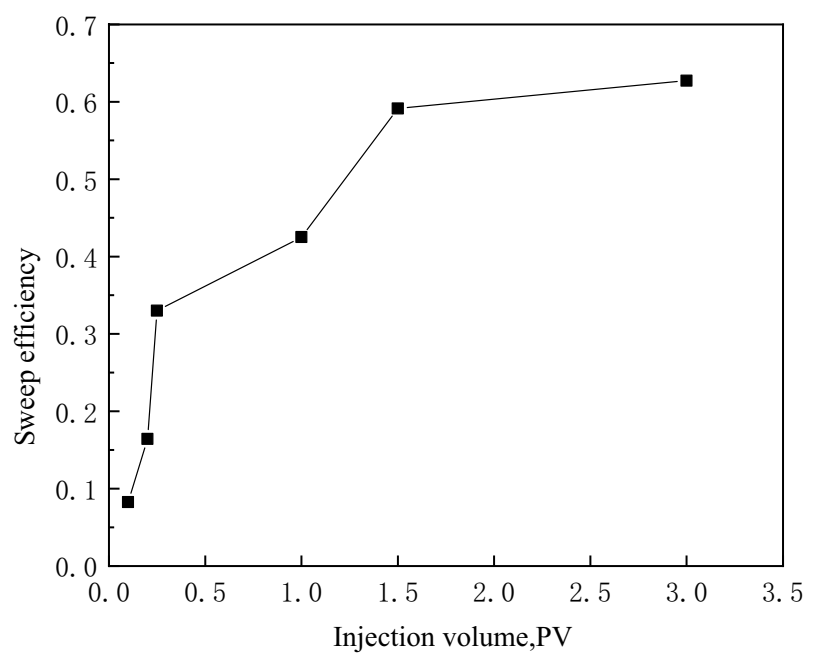

Fig. 41 The curve of sweep coefficient change under viscosity of $500 \mathrm{cp}$ and injection speed of $0.5 \mathrm{~mL} / \mathrm{min}$

viscosity decreases, the shear rate increases and the viscosity decreases.

5. The percolation experiment of crude oil core shows that when the temperature is $65{ }^{\circ} \mathrm{C}$ and $95^{\circ} \mathrm{C}$, and the pressure gradient is small, the percolation velocity increases slowly with the increase in pressure gradient, and the relationship between percolation velocity and pressure gradient is a curve of concave velocity axis. With the increase in pressure gradient, the seepage velocity increases. When the pressure gradient reaches a certain value, the seepage velocity and pressure gradient gradually become linear. When the temperature is $110{ }^{\circ} \mathrm{C}$, the seepage velocity is approximately linear with the pressure gradient.

6. The percolation experiment of crude oil core shows that the crude oil viscosity first decreases rapidly with the increase in percolation velocity and then tends to be flat, forming a power function relationship. The crude oil viscosity ranges from 600 to $730 \mathrm{cp}$ at the formation temperature of $65^{\circ} \mathrm{C}$.

7. The depletion test of crude oil shows that when the pressure is higher than the bubble point, the oil pro- duction is small, and the cumulative oil production increases slowly. When the pressure is lower than the bubble point, the oil production increases and the cumulative oil production increases rapidly. When the pressure continues to decrease, the oil production gradually decreases. When the pressure is higher than the bubble point, the gas-oil ratio remains relatively stable. When the pressure is lower than the bubble point, the gas-oil ratio fluctuates slightly, the pressure continues to decrease, and the gas-oil ratio increases rapidly.

8. The recovery degree is related to the depletion rate. The faster the depletion rate is, the higher the recovery degree is. For example, the depletion rate increased from 5 to $15 \mathrm{MPa} / \mathrm{h}$, and the recovery rate increased from 16.38 to $20.80 \%$.

9. The water flooding experiment of crude oil shows that with the increase in water injection rate, the oil seepage rate increases and the viscosity decreases, increasing the oil displacement efficiency and improving the water flooding effect.

10. After the water breakthrough, the water content of crude oil could rapidly increase to more than $80 \%$, and the crude oil can continue to be produced in the high water cut stage.

11. When the oil displacement pressure is near the bubble point pressure, the water flooding effect is the best, and the total recovery is $34.21 \%$. The water flooding effect can be improved by increasing temperature. The recovery degree of water flooding at $100{ }^{\circ} \mathrm{C}$ is $6.85 \%$ higher than that at $65^{\circ} \mathrm{C}$.

12. The experimental results of sweep efficiency of crude oil water flooding show that the injected water could break through quickly during water flooding, and the sweep efficiency will further increase after water breakthrough. The sweep efficiency decreases with the increase in crude oil viscosity but increases with increased injection speed.

This study provides technical support for the effective production of offshore heavy oil fields.

Funding The project is supported by the National Science and Technology Major Project During The 13th Five-year Plan Period "Bohai Oilfield Efficient Development Demonstration Project" (Number 2016ZX05058). The funders had no role in study design, data collection, analysis, decision to publish, or manuscript preparation.

Open Access This article is licensed under a Creative Commons Attribution 4.0 International License, which permits use, sharing, adaptation, distribution and reproduction in any medium or format, as long as you give appropriate credit to the original author(s) and the source, provide a link to the Creative Commons licence, and indicate if changes were made. The images or other third party material in this article are included in the article's Creative Commons licence, unless indicated 


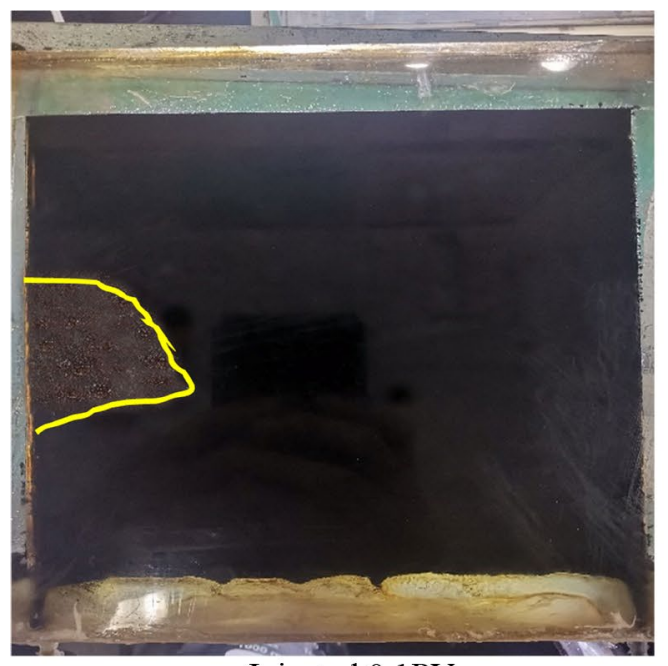

a. Injected 0.1PV

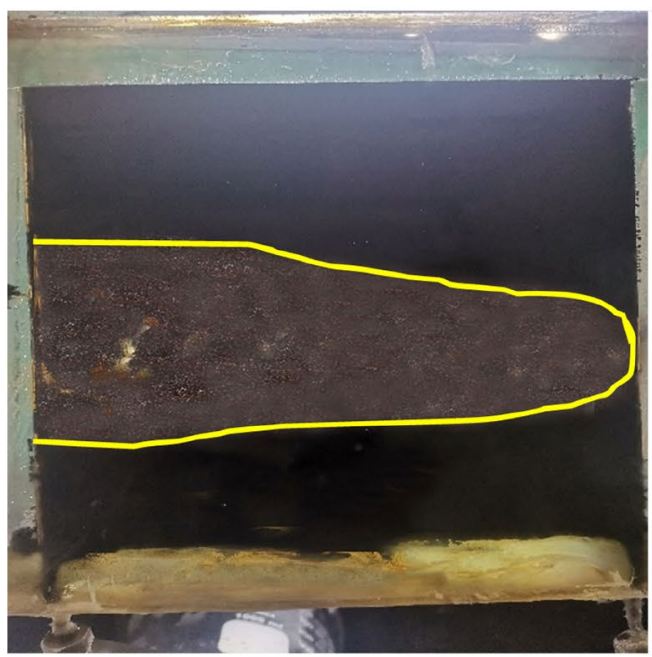

c. Water moment

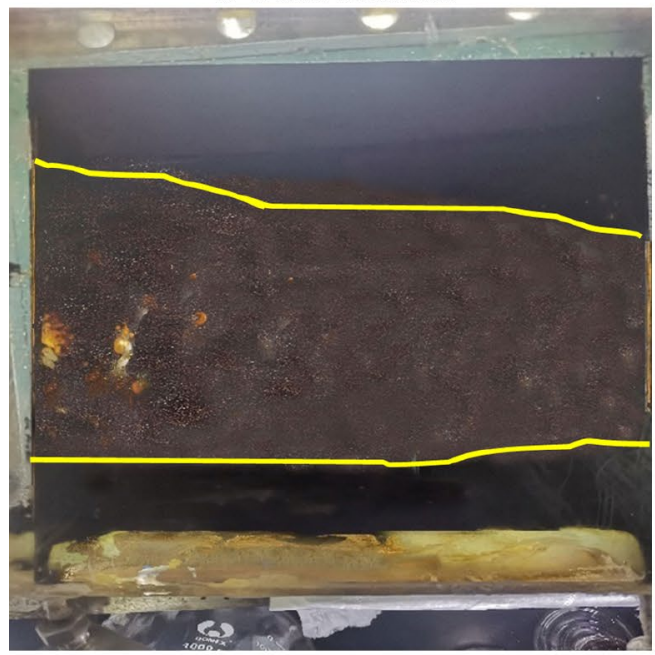

e. Injected 1.5PV

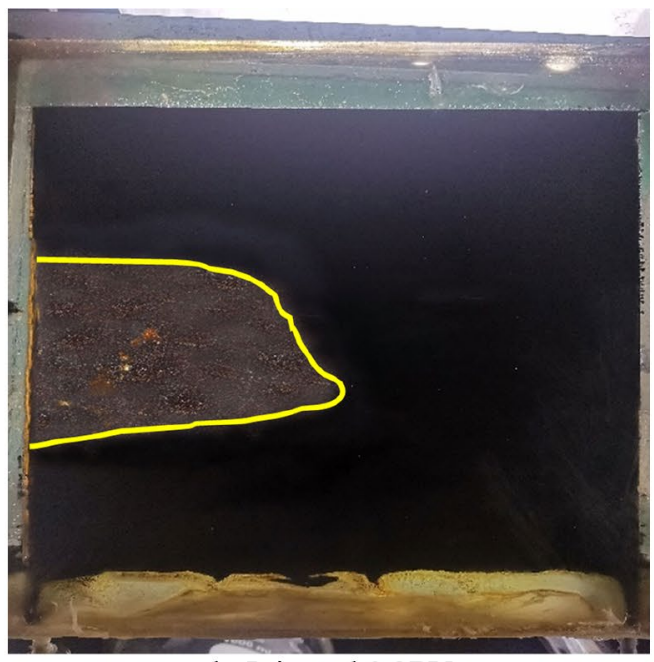

b. Injected 0.2PV

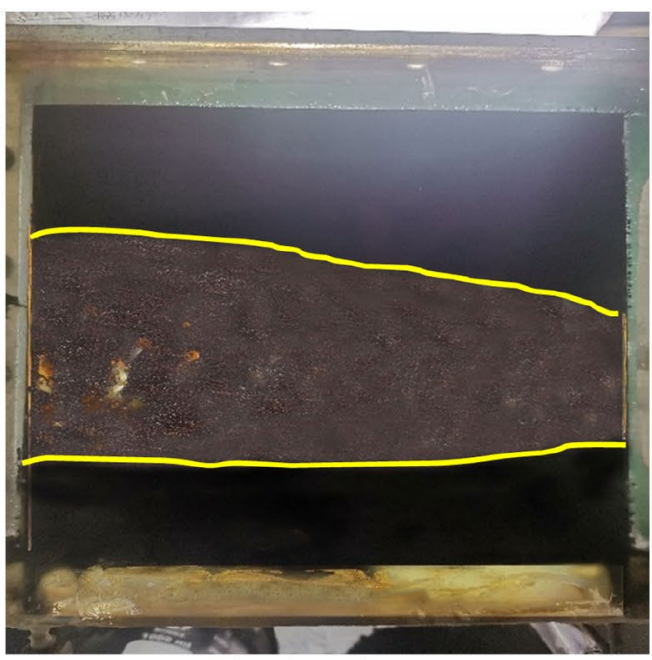

d. Injected 1PV

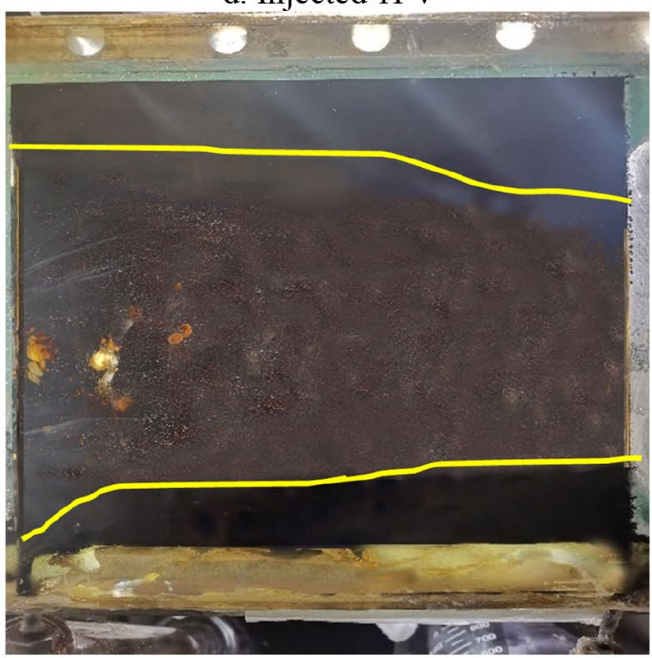

f. Injected 3PV

Fig. 42 Impact at different times under viscosity of $500 \mathrm{cp}$ and injection speed of $0.5 \mathrm{~mL} / \mathrm{min}$ 
Table 11 Experimental results of water drive sweep efficiency

\begin{tabular}{|c|c|c|c|}
\hline \multirow[t]{2}{*}{ Viscosity (cp) } & \multirow{2}{*}{$\begin{array}{l}\text { Injection speed } \\
(\mathrm{mL} / \mathrm{min})\end{array}$} & \multicolumn{2}{|c|}{ Sweep efficiency } \\
\hline & & $\begin{array}{l}\text { When water is } \\
\text { seen }\end{array}$ & Final \\
\hline \multirow[t]{2}{*}{500} & 1 & 0.33 & 0.66 \\
\hline & 0.5 & 0.24 & 0.61 \\
\hline 700 & 1 & 0.26 & 0.62 \\
\hline
\end{tabular}

otherwise in a credit line to the material. If material is not included in the article's Creative Commons licence and your intended use is not permitted by statutory regulation or exceeds the permitted use, you will need to obtain permission directly from the copyright holder. To view a copy of this licence, visit http://creativecommons.org/licenses/by/4.0/.

\section{References}

Adams DM (1982) Experiences with waterflooding lloydminster heavy-oil reservoirs. J Pet Technol 34(08):1643-1650

Li C (2016) Study on water drive potential evaluation and development adjustment strategy of narrow strip heavy oil reservoir. Dissertation, China University of Petroleum (Beijing)

Cheng W (2020) Heavy oil and water treatment technology and its application in Xinjiang Oilfield. Pet Plan Des 31(06):34-51

Guo D (2014) Research and application of cold production technology for high pour point oil in Shenyang oilfield. Dissertation, Northeast Petroleum University

Wei D (2010) Research on development mode of the heavy oil reservoir in block Gao 424. Dissertation, China University of petroleum

Dun T et al (1996) Heavy oil reservoir in China. Northwest University Press, Xi'an

Fan H, Wang Q, Liu Y et al (2006) Feasibility study on applying heavy oil cold recovery technology in Shengli oilfield. Special Oil Gas Reserv 13(1):81-83

Tong F (2017) Technical policy research on enhanced cold recovery of deep heavy oil. Dissertation, China University of Petroleum (East China)

Qu G (2014) Research on development technology of shallow heavy oil reservoir in Changchunling block. Dissertation, Northeast Petroleum University

Shi H (2013) Optimization design of thin layer heavy oil horizontal well in fault block wa 60 Liaohe Oilfield. Dissertation, Northeast Petroleum University

Sun H (2017) Study on waterflooding development law of Triassic deep heavy oil in Lukeqin. Dissertation, Northeast Petroleum University

Zheng J (2013) Research on percolation mechanism and development technology of extra-heavy oil reservoir in Wangzhuang oilfield. Dissertation, China University of Geosciences (Beijing)

Li J (2014) Study on infilling adjustment scheme of Qigu formation in Hongqian 1 well block of Xinjiang Oilfield. Dissertation, Southwest Petroleum University
Liu L (2008) Research and application of sand cold recovery technology for heavy oil in Taobao oilfield of Jilin Oilfield. Dissertation, Northwestern University

Liu W (1999) Heavy oil steam injection thermal recovery engineering. Petroleum Industry Press, Beijing

Liu P, Wu Y, Li X (2013) Experimental study on the stability of the foamy oil in developing heavy oil reservoirs. Fuel 111(9):12-19

Mai A, Kantzas A (2009) Heavy oil waterflooding: effects of flow rate and oil viscosity. J Canad Pet Technol 48(03):43-6-12

McAuliffe CD (1973) Oil-in-water emulsions and their flow properties in porous media. J Pet Technol 25(06):727-733

Zhang P (2007) Applied research on heavy oil reservoir recovery technology in the South Chenjiazhuang area. Dissertation, China University of petroleum

Zhang Q (2017) Research on matching technology for deep ultraheavy oil recovery in Es3 of Ken 119 block. Dissertation, China University of Petroleum (East China)

Qu W (2013) Heavy oil recovery status and related technology research. China New Technol New Prod 6:163-164

Wang R (2015) Study on supercritical steam huff and puff technology of ultra-deep and ultra-heavy oil in the eastern Lukeqin area. Dissertation, China University of Petroleum (East China)

Sheng JJ, Maini BB, Hayes RE et al (1997) Experimental study of foamy oil stability. J Canad Pet Technol 36:04

Wang S (2013) Study on percolation mechanism of low permeability heavy oil reservoir. Dissertation, China University of Petroleum (East China)

Singhal AK (2009) Role of operating practices on performance of waterfloods in heavy oil reservoirs. J Can Pet Technol 48(3):10-14

Wu Z, Dong B, Cheng C, Li G, Zhang Z (2007) Practice and understanding of heavy oil cold recovery in $F$ oilfield of block $L$ in Sudan. Oil Drill Prod Technol 05:75-78

Yan J, Xu H, Ma H (2015) Study on the influence of water injection quality on development index of low permeability reservoir. Inf Syst Eng 04:103

Yu Y (2017) Study on water drive development adaptability of WTG group heavy oil reservoir in J7 well block. Dissertation, Southwest Petroleum University

Zhang R, Zhu H, Liang R et al (1999) Heavy oil thermal recovery technology. Petroleum Industry Press, Beijing

Zhao K (2019) Study on cold recovery technology for heavy oil reservoir with solid edge and bottom water in zhan 29 block of Taiping Oilfield. Petrochem Technol 26(12):83-84

Zheng J (2015) Research on heavy oil cold recovery technology in the late development stage of Niuxintuo oilfield. Dissertation, Zhejiang University

Zheng S, Yang DT (2013) Pressure maintenance and improving oil recovery using immiscible water-alternating $-\mathrm{CO}_{2}$ processes in thin heavy-oil reservoirs. SPE Reserv Eval Eng 16(1):60-71

Publisher's Note Springer Nature remains neutral with regard to jurisdictional claims in published maps and institutional affiliations. 